\title{
Boundary Layer Transition Assessment on a Slender High-Speed Vehicle
}

\author{
Johan Steelant ${ }^{1}$, Andrea Passaro ${ }^{1}$, V. Fernandez-Villace ${ }^{1}$ \\ ESA-ESTEC, European Space Agency, Keplerlaan 1, 2200 AZ Noordwijk, Netherlands
}

Anatoly A. Gubanov², Dmitry S. Ivanyushkin², Yury G. Shvalev², Nina V. Voevodenko², Central Aerohydrodynamic Institute named after Professor N.E. Zhukovsky (TsAGI), 140180 Zhukovsky Moscow reg., Russian Federation

Marco Marini ${ }^{3}$, Sara di Benedetto 4 , CIRA, Italian Aerospace Research Center, Via Maiorise, 81043 Capua (CE), Italy

To anticipate the aerodynamic performance of a slender high-speed vehicle throughout a trajectory, the correct determination of transition onset and extent are crucial parameters in the overall evaluation. Though various methods and correlations are worked out on canonical geometries such as flat plates and cones, the present paper will primarily focus on a slender high-speed vehicle concept. Apart from small leading edge radii and 3D flow effects, also practical considerations are included such as gaps and steps indivertibly present due to manufacturing and integration, differential thermal expansion at dissimilar material interfaces, joints etc...

A preliminary assessment based on empirical correlations is challenged by a detailed experimental campaign supported by numerical CFD computations. Their applicability range and their limitations are assessed related to the observed flow phenomena.

\section{Nomenclature}

\begin{tabular}{|c|c|c|c|}
\hline$A \circ A$ & angle of attack & $q$ & Heat flux \\
\hline AoS & angle of sideslip & $s$ & surface \\
\hline$b$ & wing span & $T$ & temperature \\
\hline$C_{D}$ & drag force coefficient & $u, v, w$ & velocity components \\
\hline$C_{L}$ & lift force coefficient & & velocity, volume \\
\hline$C_{N}$ & normal force coefficient & $X, Y, Z$ & coordinates \\
\hline $\begin{array}{l}C_{Y} \\
D\end{array}$ & $\begin{array}{l}\text { side force coefficient } \\
\text { aerodynamic drag, diameter }\end{array}$ & & Greek Symbols \\
\hline$E$ & lift-to-drag ratio (aerodynamic efficiency) & $\alpha$ & angle of attack, local heat transfer \\
\hline$F$ & surface area of experimental sensor element & & $\begin{array}{l}\text { Coetilclent } \\
\text { angle of sideslip }\end{array}$ \\
\hline $\begin{array}{l}H, h \\
H F\end{array}$ & altitude, height, enthalpy & $\beta$ & variation, thickness \\
\hline $\begin{array}{l}H F \\
L\end{array}$ & heat flux & $\begin{array}{l}\Delta \\
\delta\end{array}$ & aileron deflection \\
\hline$L / D$ & aerodynamic efficiency $\left(\mathrm{E}_{\mathrm{ff}}\right)$ & $\varepsilon$ & emissivity coefficient \\
\hline$M$ & Mach number, pitching moment, mass & $\gamma$ & specific heat ratio \\
\hline$P$ & pressure & $\rho$ & density \\
\hline
\end{tabular}

\footnotetext{
1 Ph. D., Senior Research Engineer, ESA-ESTEC, Johan.Steelant@esa.int, Andrea.Passaro@esa.int, Victor.Villace@esa.int

2Ph. D., Head of Division, TsAGI, gubanov@tsagi.ru; Scientist, TsAGI, ivanushkin@rambler.ru;Ph.D., Leading Scientist, TsAGI, shvalev@yandex.ru; Ph.D., Head of Sector, TsAGI, nina.voevodenko@tsagi.ru

${ }^{3}$ Ph. D., Research Engineer, Aero-Space Technology Integration and Demonstrators Unit, m.marini@cira.it

${ }^{4}$ Ph. D., Research Engineer, Aeronautics - System Engineering, s.dibenedetto@cira.it.
} 


\section{Introduction}

ver the last years, various innovative concepts of civil high-speed transportation vehicles were proposed [1][2][3][4][5]. These vehicles have a strong potential to increase the cruise range efficiency at high Mach numbers. However to demonstrate the technical feasibility of these new promising concepts versus their range efficiency, performing a test flight at hypersonic speed will be the only and ultimate proof. In the framework of the EC $7^{\text {th }}$ Framework program, a dedicated international research project HEXAFLY-INT (High-Speed Experimental Fly Vehicles-International) coordinated by the European Space Agency aims at a free flight testing of an innovative high-speed glider with several breakthrough technologies on board. The scientific mission profile was worked out within the precursor project HEXAFLY [6] based upon a preliminary high-speed vehicle concept and related technologies developed within LAPCAT I \& II, ATLLAS I \& II along with the identification of the most promising launch platform. A waverider configuration was favoured to demonstrate a hypersonic gliding cruise within the atmosphere.

As aerodynamic efficiency is directly linked to the gliding performance and range capability of any aircraft, transition onset and its extent has a crucial impact on this through the friction drag of the vehicle, particularly for high speeds. The characterization of transitional boundary layer on a slender high-speed vehicle in combination with imperfections is the main goal of the present paper. Various empirical correlations for highspeed were already developed over the last decades but were mainly derived from and applicable to twodimensional flows over simple geometries such as flat plates or cones. As no alternatives were available, these correlations were used as a start to anticipate the point and extent of transition on the lee- and windward side of the vehicle. In addition, the maximum allowable perturbation size representing steps and gaps are first evaluated empirically to estimate the threshold of induced transition. The experimental verification is carried out in the low freestream turbulence wind tunnel T-116 at TSAGI supported by numerical CFD simulations to interpret correctly any 3D flow phenomena occurring at higher angles of attack whenever the classical correlations start to deviate from the experimental outcome. The general trends are discussed in function of the high-speed part of the flight trajectory around Mach 7 and $30 \mathrm{~km}$ altitude.

\section{Experimental Flight Scenario}

The Experimental Flight Test Vehicle (EFTV Figure 1) is a 3.29m long hypersonic glider with a span of about $1.23 \mathrm{~m}$. The EFTV has a two-dimensional nosetip with $2 \mathrm{~mm}$ radius and $2 \mathrm{~mm}$ lateral fillet, while the wing is characterized by a $80^{\circ}$ sweep angle, a $14^{\circ}$ negative dihedral angle, and $1 \mathrm{~mm}$ rounded leading edge. As control surfaces, the vehicle is equipped by a couple of active ailerons $(0.4 \mathrm{~m}$ long and $0.32 \mathrm{~m}$ wide) deflectable in a symmetric and asymmetric way, and a couple of fixed vertical fins characterized by a $68.5^{\circ}$ sweep angle and a $54^{\circ}$ angle formed between the two fins in the transversal plane.

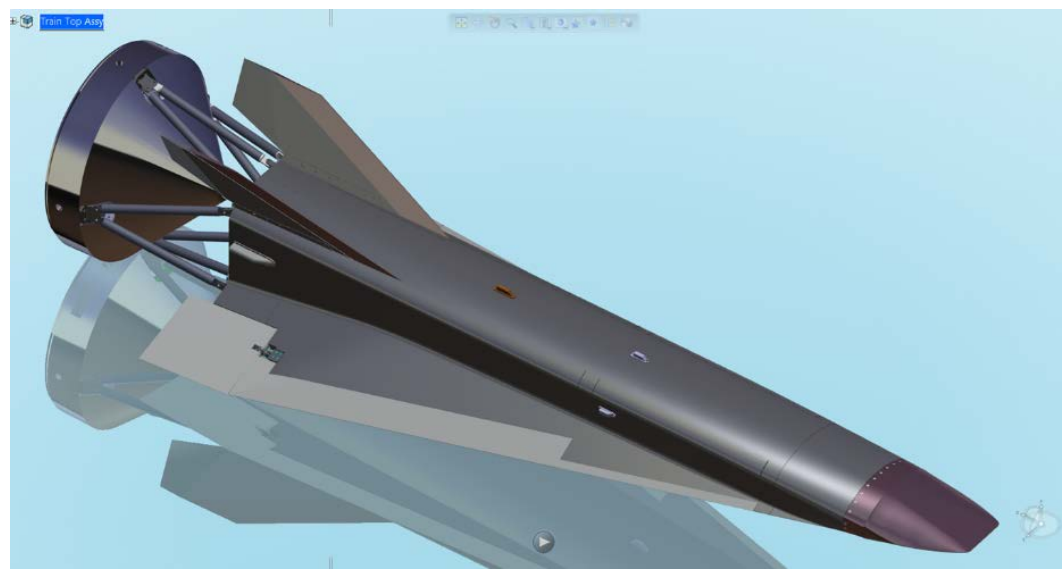

Figure 1: The EFTV glider with ESM (Experimental Support Module).

The EFTV is equipped with an avionic system composed by an inertial measurement unit, a GPS, two servo-actuators for the ailerons, and a flight control computer, which ensures the on-board mission management. An in-flight measurement system and a data acquisition system will handle the various on-board pressure, temperature and acceleration data sensors. The on-board avionics will also include a downlink 
telemetry system (i.e. with antennas) which will transmit all mission data to the Ground Control Station at the launch site.

The Experimental Flight Test Vehicle will be lifted by a sounding rocket, i.e. the Brazilian VS43 launcher equipped by an 8 ton solid rocket motor towards a suborbital trajectory having an apogee at about $90 \mathrm{~km}$. After the release from the launcher, the EFTV will perform the first part of the descent docked to the Experimental Support Module (ESM), which controls the vehicle attitude by means of a cold gas system (CGS) in concurrence with the stable aerodynamics of the ESM+EFTV train. As soon as the EFTV features full aerodynamic control, it separates from the ESM and pulls up from its descent to perform a hypersonic cruise at approximately Mach 7. In this experimental phase, the EFTV aims to demonstrate a high aerodynamic efficiency $(L / D \geq 4)$, a positive aerodynamic balance $(L \geq W)$ at controlled cruise Mach number of 7 , an optimal use of advanced high-temperature materials and structures. Further details can be found in [7][8].

The main preliminary flight sequence profile and flight events are shown and listed in Figure 2 and in Table 1 , respectively.

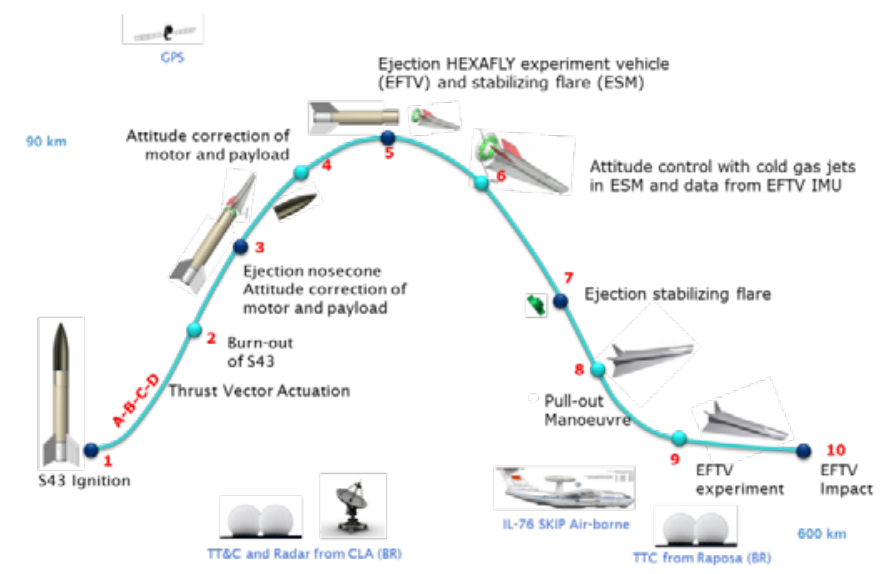

\begin{tabular}{|r|c|}
\hline \multicolumn{1}{|c|}{$\#$ F } & Flight Event \\
\hline $\mathbf{1 / 2}$ & Propelled ascent \\
\hline $\mathbf{2}$ & Motor burnout \\
\hline $\mathbf{3}$ & Nose-Cone Ejection \\
\hline $\mathbf{4}$ & L/V Alignment \\
\hline $\mathbf{5}$ & ESM/EFTV release \\
\hline $\mathbf{6}$ & Attitude control by RCS in the ESM \\
\hline $\mathbf{7}$ & Ejection of ESM \\
\hline $\mathbf{8}$ & Pull-out manoeuvre \\
\hline $\mathbf{9}$ & Controlled flight \\
\hline $\mathbf{1 0}$ & Impact \\
\hline
\end{tabular}

Table 1: Flight sequence Events

Figure 2: Flight sequence profile

\begin{tabular}{|c|c|c|c|c|c|c|c|c|c|}
\hline & $\begin{array}{l}\text { RUN } \\
\text { ID }\end{array}$ & $\begin{array}{l}\text { TIME } \\
\text { (S) }\end{array}$ & $\begin{array}{l}\mathbf{H}_{\infty} \\
\text { (M) }\end{array}$ & $\begin{array}{l}T_{\infty} \\
\text { (K) }\end{array}$ & $\mathbf{M}_{\infty}$ & $\begin{array}{l}\text { AOA } \\
\text { (DEG) }\end{array}$ & $\begin{array}{l}\mathbf{P}_{\infty} \\
\text { (PA) }\end{array}$ & $\begin{array}{c}\delta_{\text {EELEV }} \\
\text { (DEG) }\end{array}$ & $\begin{array}{c}\mathrm{H}_{0} \\
(\mathrm{MJ} / \mathrm{KG})\end{array}$ \\
\hline \multirow[t]{2}{*}{$\begin{array}{l}\text { EFTVIESM } \\
\text { SEPARATION }\end{array}$} & EFTV-065 & 273.50 & 49942.00 & 270.65 & 7.07 & 6.83 & 80.35 & -5.46 & 2.99 \\
\hline & EFTV-066 & 288.14 & 37716.85 & 244.03 & 7.46 & 12.00 & 392.18 & -15.44 & 2.98 \\
\hline \multirow{5}{*}{$\begin{array}{l}\text { MAXIMUM } \\
\text { MACH } \\
\text { MAXIMUM HEAT } \\
\text { FLUX@NOSETIP } \\
\text { MAXIMUM AOA, } \\
\text { G-LOAD } \\
\text { MAXIMUM L/D }\end{array}$} & EFTV-067 & 290.39 & 35947.24 & 239.14 & 7.50 & 12.00 & 502.25 & -15.39 & 2.94 \\
\hline & EFTV-068 & 294.44 & 33059.99 & 231.14 & 7.50 & 12.00 & 760.60 & -15.38 & 2.85 \\
\hline & EFTV-069 & 300.52 & 29936.43 & 226.45 & 7.25 & 12.00 & 1208.45 & -15.72 & 2.62 \\
\hline & EFTV-070 & 305.49 & 28652.17 & 225.17 & 7.10 & 3.62 & 1465.01 & -2.02 & 2.51 \\
\hline & EFTV-071 & 309.55 & 28040.09 & 224.57 & 7.03 & 1.63 & 1606.45 & -0.68 & 2.46 \\
\hline \multirow[t]{4}{*}{$\begin{array}{l}\text { MAXIMUM DYN. } \\
\text { PRESSURE, REL }\end{array}$} & EFTV-072 & 318.37 & 27461.55 & 223.99 & 6.88 & -0.66 & 1753.11 & 0.41 & 2.36 \\
\hline & EFTV-073 & 350.00 & 27444.96 & 223.98 & 6.42 & -1.63 & 1757.51 & 0.64 & 2.08 \\
\hline & EFTV-074 & 500.05 & 28854.96 & 225.37 & 4.80 & 0.51 & 1421.03 & -2.25 & 1.27 \\
\hline & EFTV-075 & 649.95 & 25720.26 & 222.27 & 3.46 & 0.97 & 2283.67 & -5.04 & 0.76 \\
\hline $\begin{array}{l}\text { END OF } \\
\text { MISSION }\end{array}$ & EFTV-076 & 793.56 & 20384.69 & 216.97 & 2.00 & 1.31 & 5206.06 & -6.17 & 0.39 \\
\hline
\end{tabular}

Table 2: Particular points along the trajectory of the EFTV

\section{Correlation based Estimation for Transition Onset and Extent for Clean Configuration}

Five dimensioning points were picked along the trajectory (Table 2) to assess the transitional behaviour of the boundary layer, i.e. 066, 068, 069, 070 and 071 . These points represent respectively the highest trajectory point where AoA is set to $12^{\circ}$ (ID-066), the point of maximum nose heat flux (ID-068), the lowest trajectory 
point where AoA is set to $12^{\circ}$ (ID-069), the point of maximum aerodynamic efficiency (ID-070), and the point of maximum heat flux (ID-071). Starting from the boundary layer properties derived from CIRA's CFD simulations, ESA and CIRA applied various sets of transition criteria to the fuselage $(Y=0.0 \mathrm{~m})$ and the wing $(\mathrm{Y}=0.47 \mathrm{~m})$ sections at different $X$-stations $(X=-0.2,0.0,0.5,1.0,1.5,2.0,2.5,2.75 \mathrm{~m})$ (see Figure 3). The criterion used to detect boundary layer edge from the (normal-to-wall) profiles of velocity and total enthalpy is $\mathrm{H}_{0 \mathrm{e}}=0.99 \cdot \mathrm{H}_{0}$, as described in Figure 3 (right).
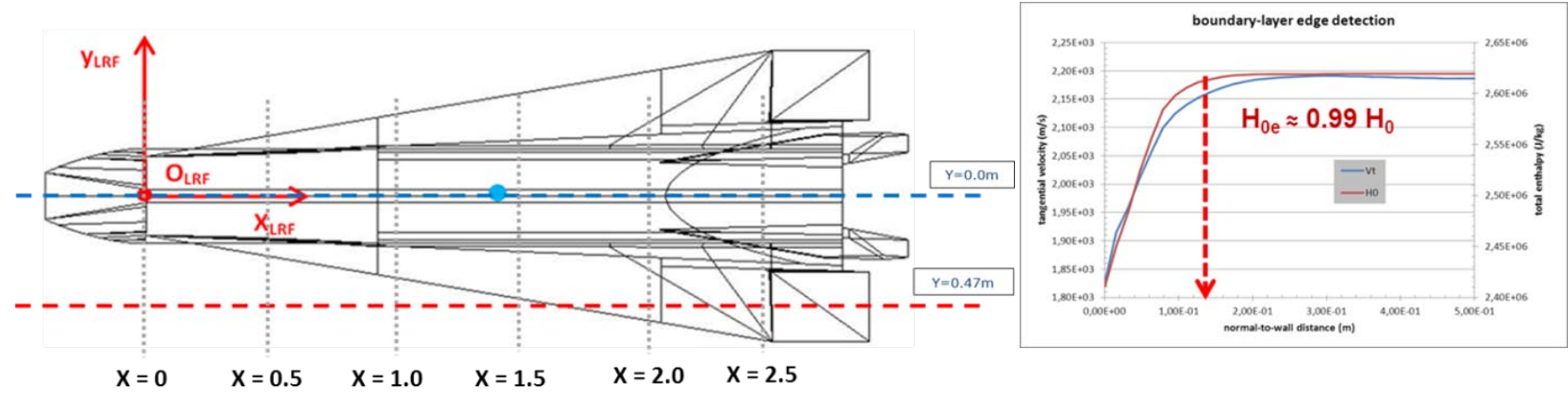

Figure 3.Planes and sections considered for the transition analysis (left) and boundary layer profile with edge detection criterion (right).

To estimate transition onset location and transition zone length, ESA applied the criteria of Simeonides [9][10][11][12]. These take into account the leading edge bluntness thickness which is defined as twice the leading edge curvature radius. For a flat plate, they are defined as:

- weak bluntness for $R e_{b}<70 \cdot M^{1.7}$ :

$$
\begin{aligned}
& R e_{x, t}=0.9 \cdot \frac{R e_{1}}{M} \\
& R e_{x, t}=70000 \cdot M^{0.08} \cdot R e_{b}{ }^{0.46} \\
& R e_{x, t}=6 \cdot 10^{6} \cdot M^{1.38} \cdot R e_{b}{ }^{-0.19}
\end{aligned}
$$$$
\text { - modest bluntness for } \operatorname{Re}_{b}<1000 \cdot M^{2} \text { : }
$$$$
\text { - strong bluntness for } R e_{b}>1000 \cdot M^{2} \text { : }
$$

For a cone, the criteria proposed is: $R e_{x, t}=5 \cdot 10^{5} \cdot M^{0.80} \cdot R e_{b} 0.1$

The transition length (in terms of $\mathrm{Re}$ ) considering the evolution along a streamline as on a flat plate:

$$
R e_{\Delta x}=\left(60+4.86 \cdot M^{1.92}\right) \cdot R e_{t}{ }^{2 / 3}
$$

The other approach for transition onset and length determination is based upon the effect of freestream perturbation on transition onset and the turbulent spot growth parameter $\hat{n} \sigma$. The latter parameter allows describing the evolution of the intermittency factor $y$ enabling the state and extent of transition at each point. Based on Mayle's correlations [13] and considering compressibility effects [14], the freestream perturbation level $T u$ is estimated indirectly using Simeonides' transition onset. The dependency of the spot growth parameter on this estimated Tu-level allows then to determine the spot growth parameter and the transitional evolution.

$$
\begin{aligned}
& R e_{\theta t, i n c, e q}=\frac{0.664 \cdot \sqrt{R e_{t}}}{\sqrt{1+0.38 \cdot M^{2}}} \longrightarrow \\
& R e_{\Delta x 2}=75 \cdot R e_{\theta t, \text { inc,eq,end_of_transition }}^{5 / 4}
\end{aligned}
$$
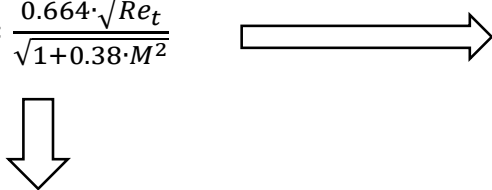

$$
\begin{aligned}
& R e_{\theta t, i n c, e q}=420 \cdot T u^{-0.69} \\
& \hat{n} \sigma_{i n c}=1.5 \cdot 10^{-11} \cdot T u^{7 / 4} \\
& \hat{n} \sigma_{M}=\hat{n} \sigma_{i n c} \cdot\left[1+0.58 \cdot M^{0.6}\right]^{-2} \\
& \gamma(x)=1-\exp \left[-\hat{n} \sigma_{M}\left(R e_{x}-R e_{t}\right)^{2}\right]
\end{aligned}
$$

For each case, the possible transition is determined at different cross sections in the streamwise direction using the local edge values. By intersecting the local distance from the leading edge with the relative transition start distance, the transition point can be determined. The use of local boundary layer edge properties allows considering indirectly the pressure gradients and other features depending on the local geometry (e.g. aileron deflection).

This transition dependence on leading edge bluntness allows also deriving optimal nose and wing leading edge radii while considering also aspects such as integration, manufacturing and integrated heat load. For the 
nose leading edge, a variation within $1 \mathrm{~mm}$ to $2 \mathrm{~mm}$ radius was preferred to cope with the stagnation heat loads. For the wing leading edges, the $\mathrm{CMC}$ parts can go down up to $0.1 \mathrm{~mm}$ radius, whereas one could easily go up to $1 \mathrm{~mm}$ without compromising integration aspects.

Two additional transition criteria were proposed by CIRA. The first criterion, due to Di Cristina [15], gives the local transition Reynolds number Rext as a function of the local edge Mach number Me:

$$
\begin{gathered}
\log _{10}\left(R e_{X t}\right)=a \exp \left(b M_{e}^{c}\right) \\
C R I T=\log _{10}\left(R e_{X t}\right) /\left[a \exp \left(b M_{e}^{c}\right)\right] \geq 1
\end{gathered}
$$

with $a=6.421, b=1.209 \cdot 10^{-4}$ and $c=2.641$. The effect of wing leading edge is also accounted for in the criterion by means of a function of wing sweep angle $\Lambda$, i.e.:

$$
\frac{\left(R e_{X t}\right)_{\Lambda}}{\left(R e_{X t}\right)_{\Lambda=0}}=0.787 \cos ^{4.346} \Lambda-0.7221 e^{-0.0991 \Lambda}+0.9464
$$

In the case of the EFTV $(\Lambda=80.1 \mathrm{deg})$ the "actual" Reynolds number is largely reduced, i.e. (Rext) $N$ $(\operatorname{Re} \times t)_{\Lambda=0}=0.318$, and this has a beneficial effect on the critical Reynolds number at which laminar-to-turbulence transition starts.

The second criterion employed is the one proposed by Berry et al. [16], and was used in the frame of the NASP andX-43A projects for boundary layer transition. It correlates the local transition Reynolds number based on momentum thickness $\operatorname{Re}_{\theta}$ to the local edge Mach number Me, i.e.

$$
R e_{\theta} / M_{e} \geq 300 \div 450
$$

\section{A. Transition on Fuselage: symmetry plane}

The outcome of the various correlations is discussed below when applied to both the wind and leeward side of the fuselage's symmetry plane $Y=0$. For the windward side and nose radius of $2 \mathrm{~mm}$, transition was detected according to Simeonides' criteria only as from point EFTV-069 onwards: transition started around 1.52-1.76 m from LE with a transition length of about 1.15 to $1.26 \mathrm{~m}$ (see Figure 4). Transition was predicted complete at the end of fuselage (2.66-3.02 $\mathrm{m}$ from LE). For case 068, beginning of transition was only found with the cone criterion at $2.4 \mathrm{~m}$ but the expansion occurring shortly after in the aft of the fuselage suppressed any further spot growth. Hence, transition could be considered eminent but not present. The prediction of transition extent among the two methodologies varied only with $10 \%$.

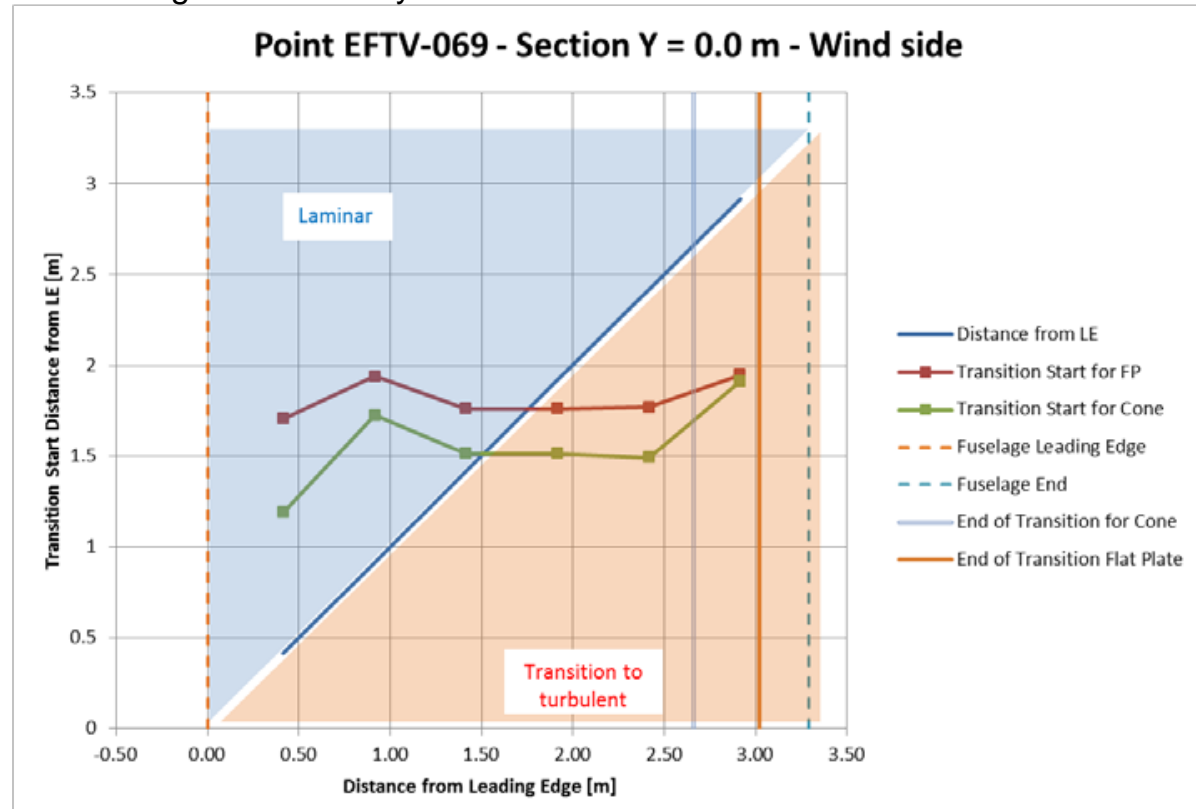

Figure 4.Transition onset estimation according to flat plate and cone correlations of Simeonides. 
In case a nose radius of $1 \mathrm{~mm}$ was selected, the transition always started earlier. Already at a higher altitude (point EFTV-068), onset was predicted around $2.2 \mathrm{~m}$ but the transitional zone was only developed to an intermittency of $15 \%$ at the trailing edge. For the point EFTV-069, the onset shifted about $10 \mathrm{~cm}$ upstream to around 1.45 to $1.65 \mathrm{~m}$ from the leading edges. Evidently, transition was also completed before the trailing edge.

For the leeward side, no transition was ever detected for both the $1 \mathrm{~mm}$ and $2 \mathrm{~mm}$ nose radius. From this evaluation, a $2 \mathrm{~mm}$ leading edge was favoured for implementation as it delayed transition on the windward side. All the results according to Simeonides' criteria are reported in Table 3.

\begin{tabular}{|c|c|c|c|c|c|c|c|c|c|c|c|c|c|c|c|}
\hline $\begin{array}{c}\text { Trajectory } \\
\text { Point }\end{array}$ & Y Section & \begin{tabular}{|c|} 
Leading \\
Edge Radius
\end{tabular} & Side & \begin{tabular}{|c|} 
Transition \\
Start FP
\end{tabular} & \begin{tabular}{|c|} 
Transition \\
End FP
\end{tabular} & Tu FP & $\begin{array}{c}\text { max } \\
\text { gamma FP }\end{array}$ & \begin{tabular}{|l|} 
Transition \\
Start Cone
\end{tabular} & $\begin{array}{l}\text { Transition } \\
\text { End Cone }\end{array}$ & Tu Cone & $\begin{array}{c}\text { max gamma } \\
\text { cone }\end{array}$ & $\begin{array}{c}\text { Trans. } \\
\text { Length FP }\end{array}$ & \begin{tabular}{|c} 
Trans. Length \\
Cone
\end{tabular} & $\begin{array}{c}\text { Trans. } \\
\text { Length } 2 \text { FP }\end{array}$ & \begin{tabular}{|c|} 
Trans. Length \\
2 Cone
\end{tabular} \\
\hline$[-]$ & [m] & [m] & {$[-]$} & [m] & [m] & [\%] & {$[-]$} & [m] & {$[\mathrm{m}]$} & [\%] & {$[-]$} & [m] & {$[\mathrm{m}]$} & {$[\mathrm{m}]$} & {$[\mathrm{m}]$} \\
\hline EFTV-066 & 0 & 0.002 & W & $\mathrm{NA}$ & $\mathrm{NA}$ & NA & $\mathrm{NA}$ & $\mathrm{NA}$ & $\mathrm{NA}$ & $\mathrm{NA}$ & $\mathrm{NA}$ & $\mathrm{NA}$ & $\mathrm{NA}$ & $\mathrm{NA}$ & $\mathrm{NA}$ \\
\hline EFTV-068 & 0 & 0.002 & w & NA & NA & NA & NA & 2.4 & NA & 0.3 & 0.01 & NA & NA & $\mathrm{NA}$ & NA \\
\hline EFTV-069 & 0 & 0.002 & $w$ & 1.76 & 3.02 & 0.32 & 1.00 & 1.52 & 2.66 & 0.36 & 1 & 1.26 & 1.14 & 1.15 & 1.06 \\
\hline EFTV-066 & 0 & 0.001 & w & NA & NA & NA & NA & $\mathrm{NA}$ & NA & NA & NA & NA & NA & NA & NA \\
\hline $\begin{array}{l}\text { EFTV-068 } \\
\end{array}$ & 0 & 0.001 & w & 2.20 & 4.02 & 0.37 & 0.15 & 2.25 & 4.23 & 0.35 & 0.17 & 1.82 & 1.98 & 1.73 & 2.50 \\
\hline EFTV-069 & 0 & 0.001 & w & 1.65 & 2.89 & 0.32 & 1.00 & 1.45 & 2.55 & 0.36 & 1 & 1.24 & 1.1 & 1.10 & 1.05 \\
\hline
\end{tabular}

Table 3: Transition onset and extent predictions

Di Cristina and Berry criteria predicted also a fully laminar flow on the leeside. On the windside, laminar flow is predicted by Di Cristina's criterion whereas transition is predicted by NASP criterion at the very rear of the fuselage: $2.55 \mathrm{~m}$ from nosetip at $33.06 \mathrm{~km}$ and $2.30 \mathrm{~m}$ from nosetip at $29.93 \mathrm{~km}$. Results are reported in Figure 5 for the section $Y=0.0 m$ (fuselage) where $X=0$ is located at the nose tip.
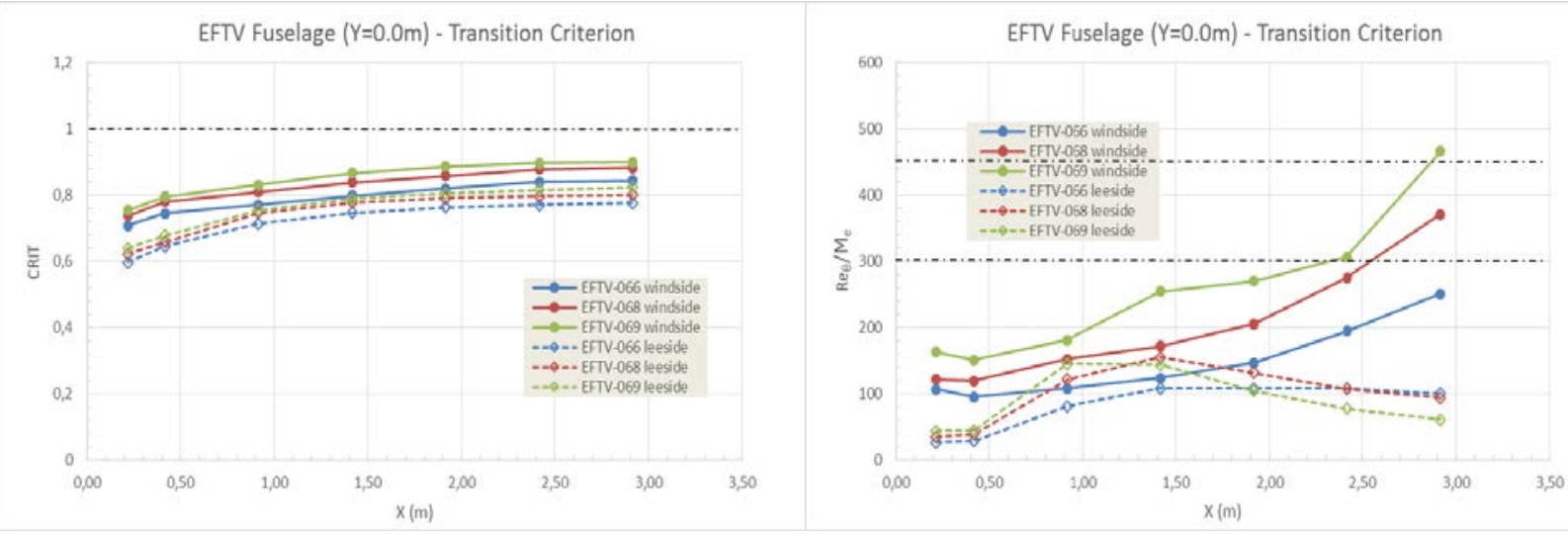

Figure 5. EFTV laminar-to-turbulence natural transition (fuselage): Di Cristina criterion (left) and X-43A criterion (right).

\section{B. Transition on wing}

For the wing, no transition was found on the lee-side in the investigated plane. For the windside, results are strongly dependent on the leading edge radius of curvature: used values were 1.0, 0.5, 0.25 and $0.1 \mathrm{~mm}$. Only data obtained with the flat plate criterion were used.

- $\quad 0.1 \mathrm{~mm}$ radius: starts around $2.16 \mathrm{~m}$ and is practically completed at the end of the wing section with exception of point EFTV-069 were a strong effect of the aileron expansion is seen.

- $\quad 0.25 \mathrm{~mm}$ radius: starts around $\mathrm{x}=2.5 \mathrm{~m}$ and only partially completed at trailing edge.

- $0.5 \mathrm{~mm}$ radius: transition is not happening until the very end of the wing section.

- $1 \mathrm{~mm}$ radius: transition never starts.

Hence $1 \mathrm{~mm}$ radius was finally selected for the design which allowed both easer integration and heat load handling. This result is also confirmed by the Di Cristina's criterion, displayed for the lower altitude case (069) in Figure 6. Fully laminar flow both at leeside and windside is predicted (the effect of aileron's negative deflection is observed, too), due to the beneficial effect of wing sweep that strongly reduces local Reynolds number. 


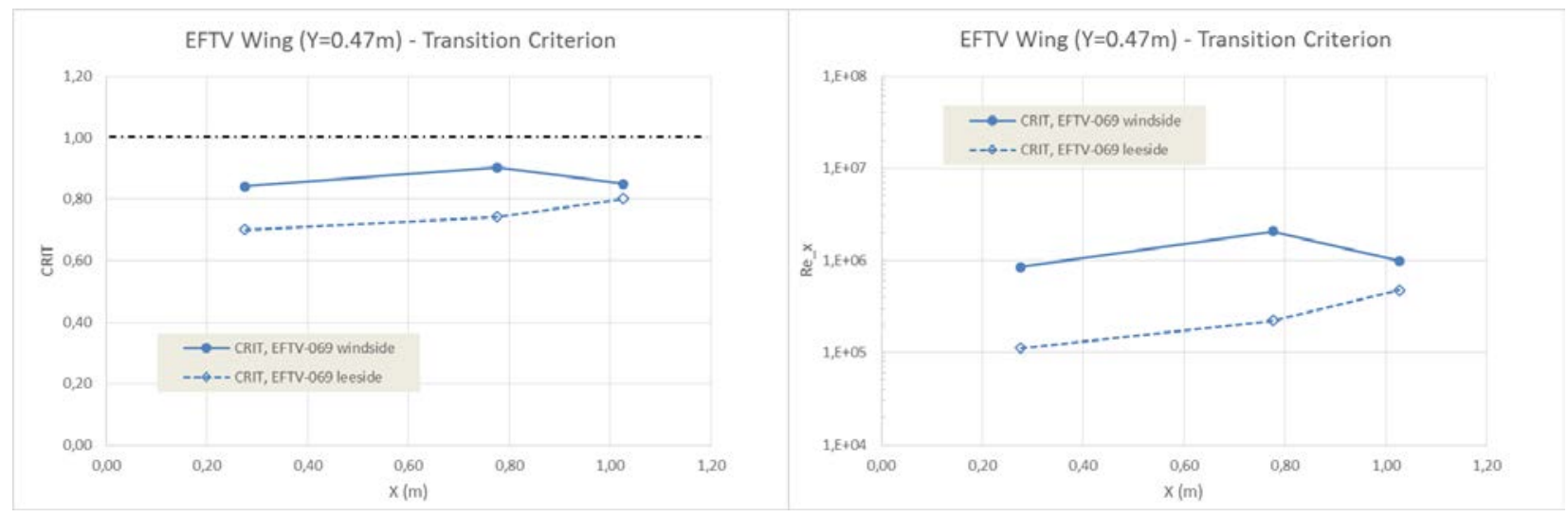

Figure 6. EFTV laminar-to-turbulence natural transition (wing): Di Cristina criterion (left) and local Reynolds number (right).

\section{Comparison CIRA vs ESA}

Table 4 provides the comparison concerning the transition starting point for altitudes $37.71,33.06$, and 29.93 $\mathrm{km}$ between CIRA and ESA. Only the windward sides were compared, because no transition was always predicted for the leeward sides. A general agreement is found, with no transition detected for the first point at $37.71 \mathrm{~km}$, a relative late one for the one at $33.06 \mathrm{~km}$ and clear transition happening only at the lowest altitude. In this case a significant difference is found between ESA and CIRA: both criteria used at ESA predict transition starting between 1.5 and $1.75 \mathrm{~m}$ (average of $1.65 \mathrm{~m}$ ), while the ones used at CIRA predict the start much more downstream $(2.3 \mathrm{~m})$. No clear reason for this discrepancy could yet be identified.

\begin{tabular}{|c|c|c|c|c|}
\hline $\begin{array}{c}\text { Trajectory } \\
\text { Point }\end{array}$ & Y Section & Side & $\begin{array}{c}\text { Transition } \\
\text { Start CIRA }\end{array}$ & $\begin{array}{c}\text { Transition } \\
\text { Start ESA }\end{array}$ \\
\hline$[-]$ & {$[\mathrm{m}]$} & {$[-]$} & {$[\mathrm{m}]$} & {$[\mathrm{m}]$} \\
\hline EFTV-066 & 0 & $\mathrm{~W}$ & NA & NA \\
\hline EFTV-068 & 0 & W & 2.55 & $>2.4$ \\
\hline EFTV-069 & 0 & W & 2.3 & 1.65 \\
\hline
\end{tabular}

Table 4: Transition onset prediction comparison.

\section{Estimation for Transition Onset in Presence of Local Imperfections}

Imperfections in smoothness of vehicle's surface can be present through design (i.e. presence of different parts composing the surface, different materials, different parts thickness), manufacturing and tolerances, assembly procedures and tolerances, flight conditions (different materials behaviour due to thermal expansion rate and stiffness, thermal and structural loads). For a high-speed vehicle, it is important to define admissible values of imperfections to alleviate

- local overheating of the material

- Impact on the boundary layer state: laminar to turbulent transition can change heat flux and skin friction with a factor 3 or more

- Impact on total thermal load the vehicle experiences along the flight trajectory

- flap efficiency degradation

- hot sneak flow into the internal part of the vehicle

The critical step height causing transition is strongly dependent on the vehicle's geometry and on the development of the boundary layer; therefore literature correlations are not always directly applicable and dedicated wind tunnel experiment reproducing the most critical flight conditions are the preferable solution to define a more reliable step requirement. Therefore, a dedicated test campaign was foreseen at TSAGI T-116 facility and is described in the next section.

To set a preliminary requirement, first the most critical locations for step/gap induced transition have been identified in the nose/fuselage and wing/leading edge junctions. Furthermore, the identification of critical 
heights for laminar to turbulent transition needs to be compatible with the manufacturing feasibility and integration implications. These were estimated along the fuselage and wing to be maximum $0.1 \mathrm{~mm}$ whereas differential thermal expansion was shown to be lower than $0.1 \mathrm{~mm}$. Hence, a total perturbation height expected along the full flight trajectory would not go beyond $0.2 \mathrm{~mm}$.

To have a preliminary indication of the critical step height, the correlations from the test campaign on forced boundary layer transition on X-43 (Hyper-X) [17] were applied to the EFTV. The choice was driven by the strong similarity between the two configurations and flight conditions; at a disadvantage, the test campaign on $\mathrm{X}-43$ was dedicated to promote the transition of the flow, therefore implementing very effective distributed roughness, and leading to conservative height values with respect to a step.

The $\mathrm{X}-43$ correlation is based on the ratio $\mathrm{k} / \delta$, where $\mathrm{k}$ is the critical step height causing transition and $\delta$ the local boundary layer thickness. Applying the same correlation at the EFTV nose/fuselage junction on windside and identifying $29.93 \mathrm{~km}$ altitude as the sizing flight condition (combination of highest AoA and low altitude) with a computed local boundary layer thickness of $1.89 \mathrm{~mm}$, it suggests that transition is triggered at an altitude lower than $30 \mathrm{~km}$ with a roughness height of $1.2 \mathrm{~mm}$ at the nose/fuselage interface.

To have a refined estimation for critical perturbation heights at hand, a literature survey of critical twodimensional roughness heights on boundary layer transition was performed and is summarized below.

Though the transition experiments by Schrijer et al. [18] and Masutti et al. [19] occurred downstream the stagnation point of bluff bodies, the boundary layer was shown to be recovered towards a self-similar profile with a regular Stanton evolution. Schrijer et al. showed that the heat flux ratio with respect to a smooth configuration hardly changed for backward or forward facing steps indicating no earlier transition triggering within the explored range of step height (Figure 7). This is not the case for 3D isolated or distributed roughness which trigger transition once a certain critical height is reached.

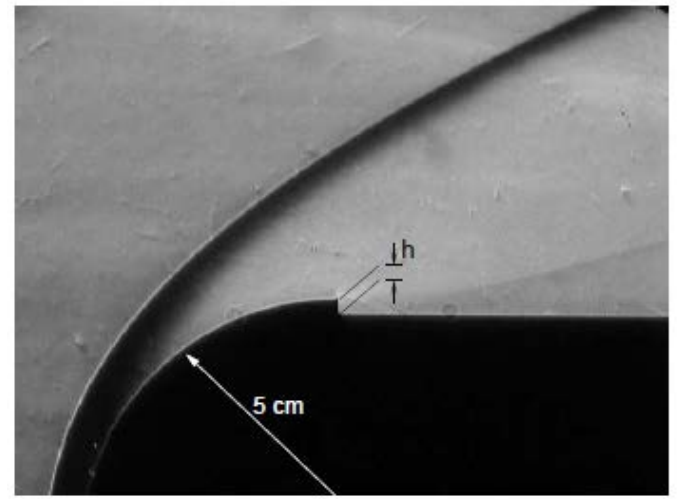

Figure 1. Schlieren image of the flow around the model $\left(h=-3.2 \mathrm{~mm}, M=9\right.$ and $\left.R e_{L}=2.4 \times 10^{6}\right)$.

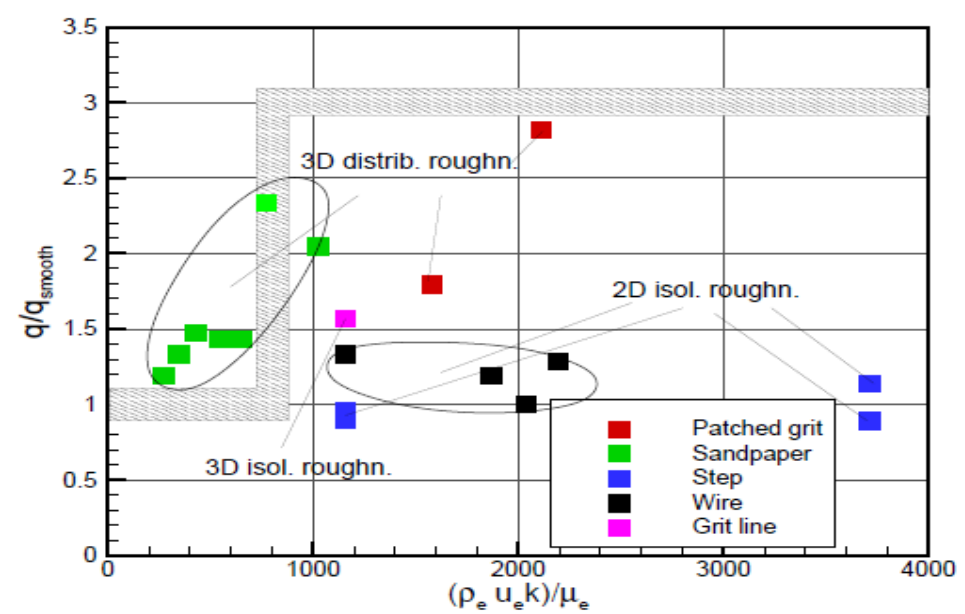

$\left(\rho_{e} u_{e} k\right) / \mu_{e}$

Figure 7: Stepwise, 3D isolate and 3D distributed roughness on EXPERT-like configuration [18]

A similar experimental campaign was carried out by Masutti et al. [19] on the real EXPERT configuration. In Figure 8 the Stanton number is plotted for flows exposed to different step heights in two different planes. For $\varphi=0^{\circ}$, the flow faces an expansion towards a flat plate with hardly a pressure gradient apart near the deflected flap in the end. The flow seems to be very tolerant with respect to 2D perturbations. For $\varphi=45^{\circ}$, located in between the flaps, the flow is still to be treated as conical which is experiencing cross-flow. This cross-flow enhances of course the growth of any induced Görtler vortical structure as can be seen on the right of Figure 8. However, beyond a certain height, the induced recirculation zone will trigger the appearance of Görtler vortices which become apparent in skin friction measurement as from $h / \delta>2 \div 2.5$. One might question whether this observation made on a blunt body is applicable to a sharp leading edge such as for the EFTV or as for the previous set of data $(\mathrm{X}-43)$ due to the different boundary layer evolution. However, the same behaviour was also observed by Ginoux [21][22] based on flat plate experiments with sharp leading edge which were positioned either perpendicular or swept with respect to the freestream. Similar observations were made by Masutti [20] on cones with sharp and slightly blunted noses Figure 10. Also here the Stanton number started to increase once a critical step height was reached and the induced Görtler vortices enhanced the transition due to the cross-flow. In particular cases on a cone geometry Figure 10, Passaro and Cifali [23][24] even found a ring geometry to have a stabilizing effect on the transition with growth postponed to a later stage. 


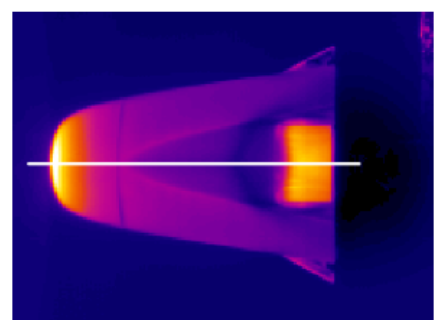

(a) Infrared picture for configuration $\phi=$ $0^{\circ}, R e=26 \times 10^{6} / \mathrm{m}$

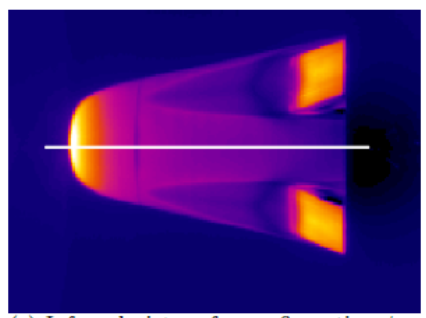

(c) Infrared picture for configuration $\phi=$ $45^{\circ}, R e=26 \times 10^{6} / \mathrm{m}$

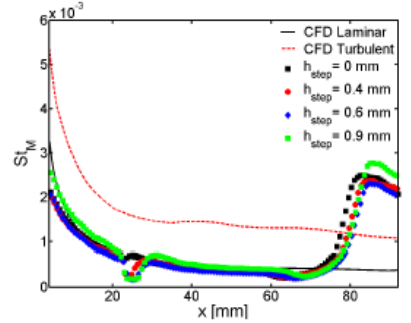

(a) $\phi=0^{\circ}, h=0.4$ to $0.9 \mathrm{~mm}, R e=26 \times 10^{6} / \mathrm{m}$

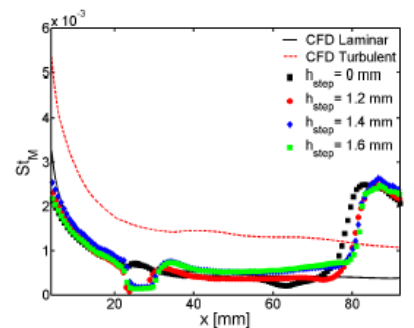

(c) $\phi=0^{\circ}, h=1.2$ to $1.6 \mathrm{~mm}, R e=26 \times 10^{6} / \mathrm{m}$

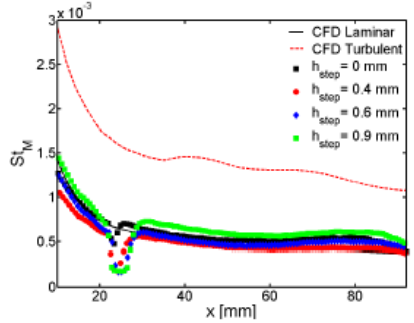

(b) $\phi=45^{\circ}, h=0.4$ to $0.9 \mathrm{~mm}, R e=26 \times 10^{6} / \mathrm{m}$

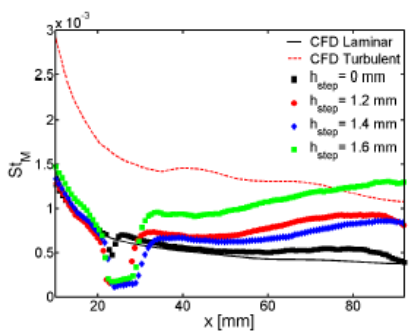

(d) $\phi=45^{\circ}, h=1.2$ to $1.6 \mathrm{~mm}, R e=26 \times 10^{6} / \mathrm{m}$

Figure 8: Backward facing steps on bluff bodies (EXPERT)
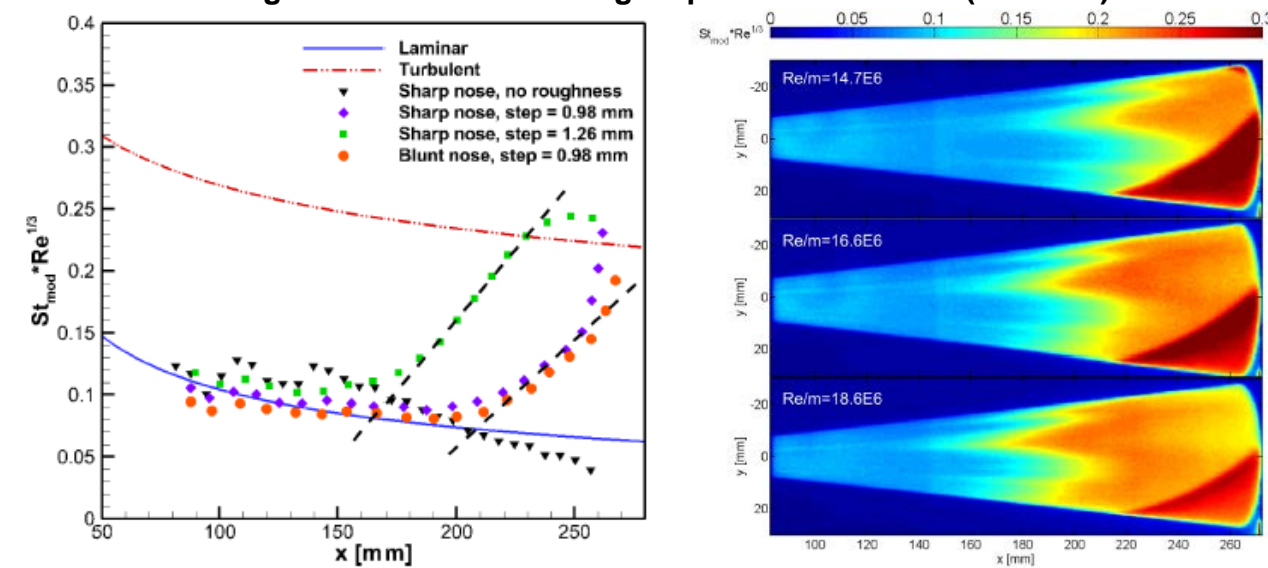

Figure 9: Backward facing steps on cones with sharp and slightly bluff leading edge[20]

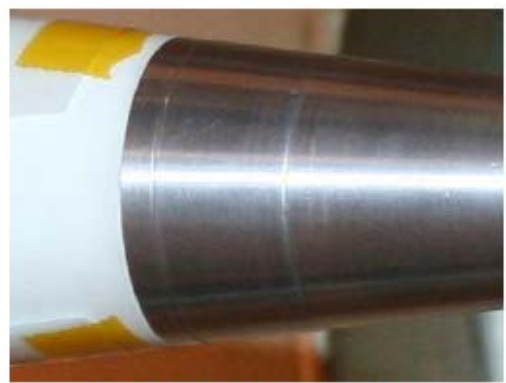

No-roughness element

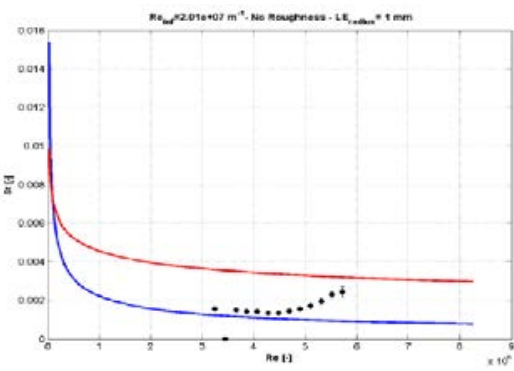

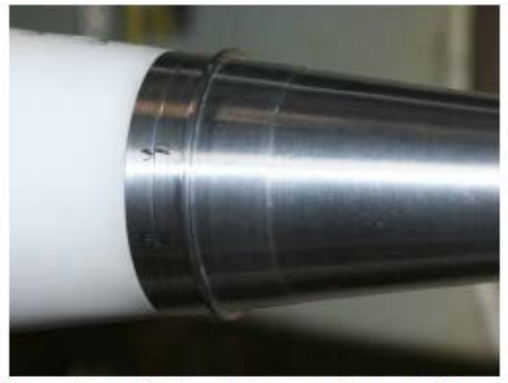

Circumferential roughness element $(1 \mathrm{~mm})$

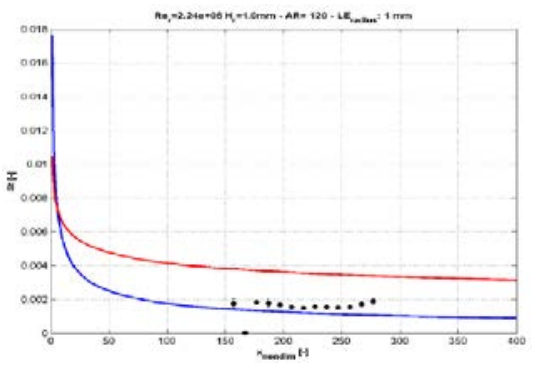

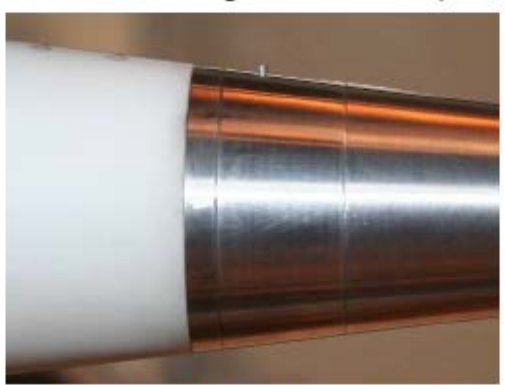

Single cylindrical roughness element

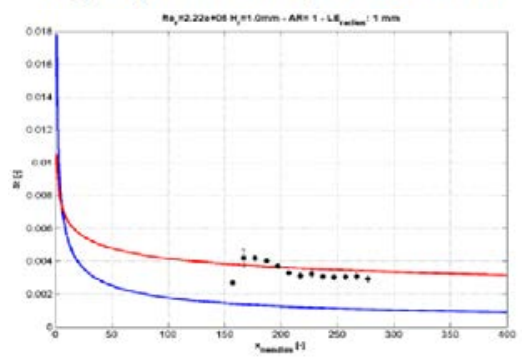

Figure 10: Stabilizing effect of 2D roughness vs 3D isolated roughness on cone

American Institute of Aeronautics and Astronautics 
As a general observation, one could state that:

1. Isolated or distributed roughness triggers transition earlier and rapidly

2. Steps or $2 \mathrm{D}$ roughness are close or similar to natural transition up to a certain step height.

3. Above a certain critical step height, Görtler instability might take over

4. If a step is followed by expansion, the transition is susceptibility postponed

Therefore, the design philosophy aims to

1. Avoid any isolated roughness

2. Avoid or minimize the step height

3. Backward facing step to be preferred above forward facing step: avoiding overheating

4. Verification and assessment of the step requirement with respect to manufacturing feasibility.

The following criteria for estimating the critical heights triggering earlier transition were derived from the literature survey described above:

$\begin{array}{lll}\text { 2D steps: } & \frac{h}{\delta}=344.45 \frac{M}{R e_{\theta}} \\ \text { Protuberances: } & \frac{h}{\delta}=27 \frac{M}{R e_{\theta}} \\ \text { Görtler: } & \frac{h}{\delta}=2\end{array}$

In the tables below, an estimation is given of the maximum step heights allowed to avoid triggering earlier transition at different stations along the fuselage and wing (windward or leeward). The overall maximum step height based on the three trajectory points for fuselage elements is predicted to be $3.7 \mathrm{~mm}$. The overall maximum step height based on one trajectory point for CMC leading edge and wing interface is $4.3 \mathrm{~mm}$.

\begin{tabular}{|c|c|c|c|c|c|c|c|c|c|}
\hline Analytical & & & X-Section & Nose-Fus & & & & & Hinge \\
\hline $\begin{array}{c}\text { Trajectory } \\
\text { Point }\end{array}$ & Y Section & Type & Side & 0.000 & 0.500 & 1.000 & 1.500 & 2 & 2.5 \\
\hline EFTV-066 & 0 & BFS & $w$ & 0.0106 & 0.0192 & 0.0184 & 0.0174 & 0.0159 & 0.0220 \\
\hline EFTV-068 & 0 & BFS & W & 0.0056 & 0.0098 & 0.0094 & 0.0089 & 0.0080 & 0.0116 \\
\hline EFTV-069 & 0 & BFS & W & 0.0037 & 0.0063 & 0.0056 & 0.0056 & 0.0053 & 0.0074 \\
\hline EFTV-066 & 0 & Gö & W & 0.0083 & 0.0158 & 0.0191 & 0.0215 & 0.0229 & 0.0288 \\
\hline EFTV-068 & 0 & Gö & w & 0.0062 & 0.0114 & 0.0139 & 0.0157 & 0.0165 & 0.0213 \\
\hline EFTV-069 & 0 & Gö & W & 0.0053 & 0.0094 & 0.0108 & 0.0125 & 0.0138 & 0.0171 \\
\hline \multicolumn{3}{|c|}{ Maximum step height } & & 0.0037 & 0.0063 & 0.0056 & 0.0056 & 0.0053 & 0.0074 \\
\hline EFTV-066 & 0 & BFS & $\mathrm{L}$ & 0.1706 & 0.1579 & 0.1385 & 0.1330 & 0.1350 & 0.1431 \\
\hline EFTV-068 & 0 & BFS & $\mathrm{L}$ & 0.1042 & 0.0910 & 0.0801 & 0.0810 & 0.0849 & 0.0926 \\
\hline EFTV-069 & 0 & BFS & $\mathrm{L}$ & 0.0673 & 0.0651 & 0.0560 & 0.0558 & 0.0579 & 0.0597 \\
\hline EFTV-066 & 0 & Gö & $\mathrm{L}$ & 0.0295 & 0.0416 & 0.0490 & 0.0558 & 0.0632 & 0.0713 \\
\hline EFTV-068 & 0 & Gö & $\mathrm{L}$ & 0.0234 & 0.0321 & 0.0376 & 0.0442 & 0.0510 & 0.0587 \\
\hline EFTV-069 & 0 & Gö & $\mathrm{L}$ & 0.0192 & 0.0274 & 0.0316 & 0.0373 & 0.0430 & 0.0477 \\
\hline \multicolumn{3}{|c|}{ Maximum step height } & & 0.0192 & 0.0274 & 0.0316 & 0.0373 & 0.0430 & 0.0477 \\
\hline
\end{tabular}

Table 5: Estimated critical step heights on fuselage triggering earlier transition.

\begin{tabular}{|c|c|c|c|c|c|c|}
\hline Analytical & & \multicolumn{2}{r|}{ X-Section } & & Hinge & \\
\hline $\begin{array}{c}\text { Trajectory } \\
\text { Point }\end{array}$ & Y Section & Type & Side & $\mathbf{2}$ & $\mathbf{2 . 5}$ & $\mathbf{2 . 7 5 0}$ \\
\hline EFTV-069 & 0.47 & BFS & W & 0.0045 & 0.0047 & 0.0188 \\
\hline EFTV-069 & 0.47 & Gö & W & 0.0043 & 0.0073 & 0.0162 \\
\hline \multicolumn{2}{|c|}{ Maximum step height } & & 0.0043 & 0.0047 & 0.0162 \\
\hline & & & & & & \\
\hline EFTV-069 & 0.47 & BFS & L & 0.0707 & 0.1229 & 0.0379 \\
\hline EFTV-069 & 0.47 & Gö & L & 0.0164 & 0.0356 & 0.0231 \\
\hline \multicolumn{2}{|c|}{ Maximum step height } & & 0.0164 & 0.0356 & 0.0231 \\
\hline
\end{tabular}

Table 6: Estimated step heights on wing being below the threshold triggering earlier transition.

\section{Experimental Wind Tunnel Campaign}

Experimental investigation of the boundary layer state and transition on the EFTV Glider surface were performed at the TsAGI supersonic and hypersonic wind tunnel T-116 having a working chamber with a squared cross-section of $1 \mathrm{~m} \times 1 \mathrm{~m}$ size. The flow was electrically heated. The windtunnel model was produced at a scale of 0.35 with respect to the size of the real EFTV vehicle. The windtunnel model and a general view of the wind tunnel are presented in Figure 11. The tests were conducted at Mach number $\mathrm{M}=7$ and angles-of-attack of the model $A o A=0,2^{\circ}, 3.6^{\circ}$, and $12^{\circ}$. The flow parameters realized in the working chamber of T-116 during tests are shown in Table 7. 


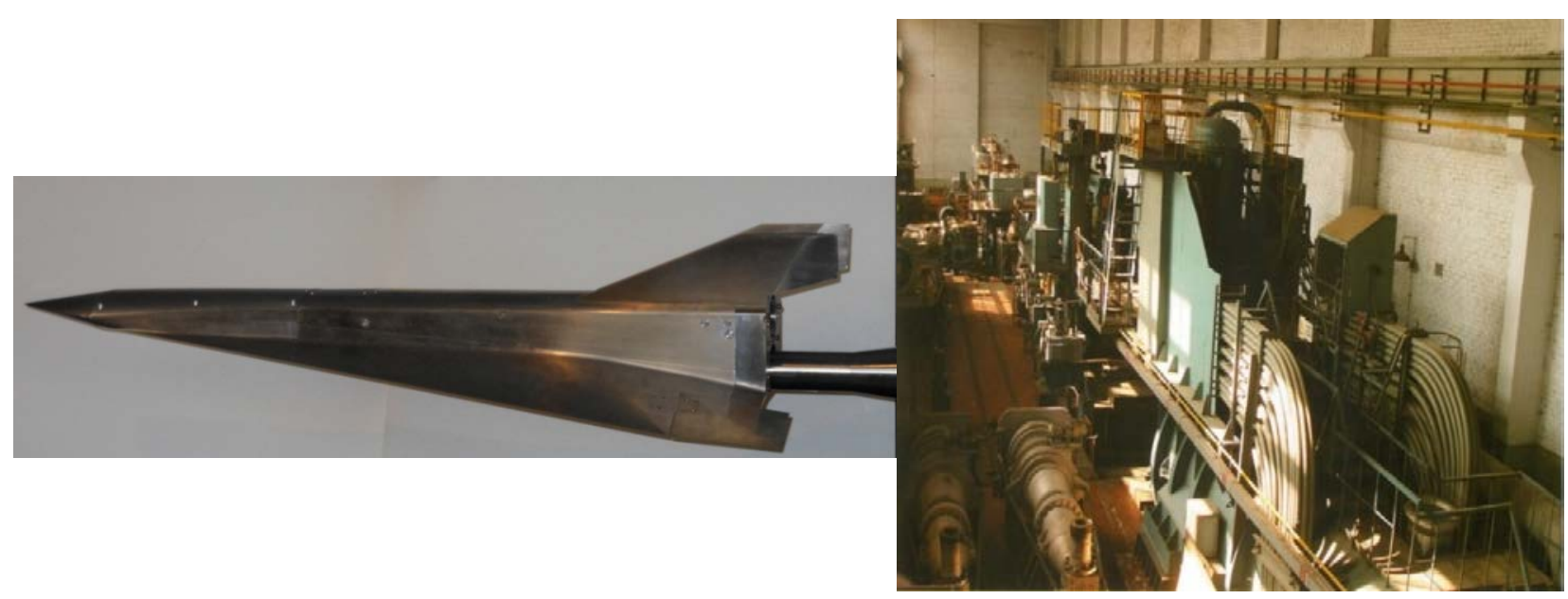

Figure 11: EFTV wind tunnel model and T-116 wind tunnel at TsAGI

\begin{tabular}{|c|c|c|c|c|}
\hline M & P tot, atm & $\mathrm{T}_{\text {tot, }} \mathrm{K}$ & $\mathrm{Re}_{1 \mathrm{M}} \mathbf{1 0}^{-6}$ & $\begin{array}{c}\text { Simulated flight } \\
\text { altitude H, km }\end{array}$ \\
\hline $\mathbf{6 . 9 9}$ & 22 & 675 & 7.66 & 30 \\
\hline
\end{tabular}

Table 7: Freestream conditions at the T-116

To study the influence of surface imperfections such as steps and gaps on boundary layer transition, the model was tested both asa smooth surface, and with transition grits of two different types: (a) cylindrical screws of diameter $2 \mathrm{~mm}$ and heights $\mathrm{k}_{\mathrm{s}}=0.35,0.7$ and $1.4 \mathrm{~mm}$, and (b) wires of diameters $\mathrm{k}_{\mathrm{w}}=0.5,1.0$ and $2.5 \mathrm{~mm}$. The roughness elements (screws and wires) were installed on the body windward and leeward surfaces downstream the junction of the nose part and the main part of the body. The axes of the roughness elements were placed at a distance of $2 \mathrm{~mm}$ from the junction. Figure 12 shows the forward windward side of the model with screws and wires installed.
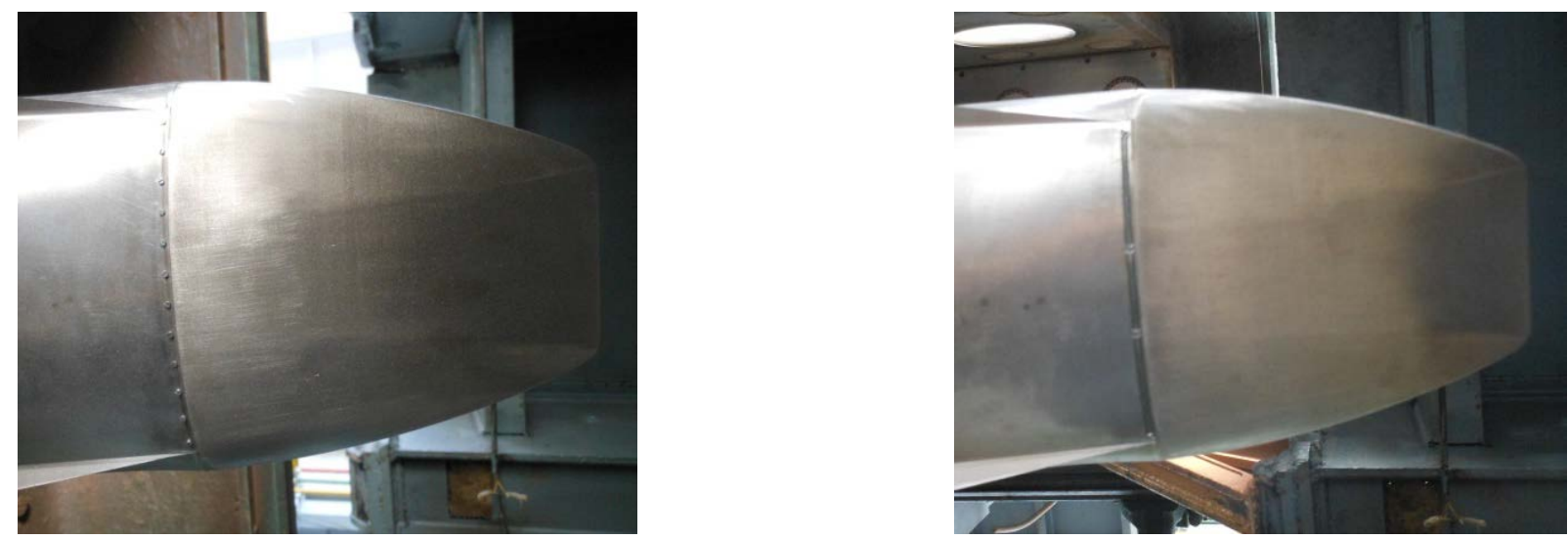

Figure 12: Position of perturbation elements just downstream of nose-fuselage junction: screws (left) and wires (right)

The screws were installed with an intermediate distance of $10 \mathrm{~mm}$ between their axes: 12 screws on the windside of the model and 14 screws on the leeside. The wires, as seen from the picture, are fixed by small screws on their ends and additionally in two intermediate points.

Laminar-to-turbulent boundary layer transition on the model surface was investigated using the so called 'regular heating regime method'. The method is based on significant difference between the local heat transfer coefficients on the model surface corresponding to laminar and turbulent boundary layers. Local heat transfer coefficients are determined measuring the rate of temperature change on specially prepared elements of the model surface during the wind-tunnel tests. The method was developed by G.M. Kondratiev [32] and further 
modifications were elaborated in several subsequent scientific works. The hypothesis of the method suggests that the logarithm of the 'temperature excess' (i.e. the difference between the local surface temperature and the recovery temperature) changes linearly with time at any point on the model surface:

$$
\ln \left(T_{r}-T_{w}\right)=-m \tau+c
$$

The value $m$ characterizes the rate of temperature change during the heating-up or cooling-down of the model, and ' $\tau$ ' is time. Applying the above equation at two moments in time, $\tau_{1}$ and $\tau_{2}$, one can write the expression:

$$
m=\frac{\ln \left(T_{r}-T_{w 1}\right)-\ln \left(T_{r}-T_{w 2}\right)}{\tau_{2}-\tau_{1}}
$$

The above formula allows determining the value of $m$ directly from the windtunnel tests. However, it is necessary to choose the appropriate set of the experimental data for which the value of $\ln \left(T_{r^{-}} T_{w}\right)$ evolves linearly with time $\tau$. During this 'regular heating regime', the value of $m$ is directly proportional to the 'local heat transfer coefficient' $\alpha$ and the external cylindrical surface area $F$ of the temperature sensor element, while being inversely proportional to the 'heating capacity' $C_{V}=c \cdot \rho \cdot V$ of the considered sensor element where $V, \rho$ and $c$ are respectively the volume, density and heat capacity of the sensing material::

$$
m=\psi \frac{\alpha F}{C_{V}}
$$

This relation follows from the energy conservation law for 'regular heating' (or 'regular cooling ') regime of the sensor element. The heat transfer coefficient $\alpha$ could be determined as:

$$
\alpha=\frac{1}{\psi} \frac{C_{V}}{F} m
$$

On the other hand, if we are considering the flat model element where $V=F \cdot \Delta$ with $\Delta$ the height of the cylindrical pillar (here set at $3.2 \mathrm{~mm}$ and equals to the local thickness of the model surface element), we obtain:

$$
\alpha=\frac{1}{\psi} m c \rho \Delta
$$

The value $\psi$, labelled as 'non-uniform temperature distribution parameter', represents the ratio of the 'excessive temperature averaged by surface' to the 'excessive temperature averaged by volume' for the considered model element. For this experiment, we were to ensure that the conditions could guarantee to have a value $\psi$ to be close to unity: $\psi \approx 1$. To achieve this, the surface sensor elements were manufactured as shown on the picture below (Figure 12). Cylindrical grooves were milled from the inside into the windtunnel model surface, resulting into a remaining cylindrical pillar with a diameter of $\varnothing=4 \mathrm{~mm}$. This pillar is still connected circumferentially towards the surrounding model surface through a small remaining thickness of $0.5 \mathrm{~mm}$ bridging a gap of $1 \mathrm{~mm}$. In such a manner, the cylindrical pillar becomes almost thermally isolated from the surrounding surface. As the model is made from metal with high thermal conductivity, the condition of $\psi \approx$ 1 is ensured. Thermocouples were installed by soldering from the inside to the centre of these cylindrical pillars. All the other elements for temperature measurements by thermocouples on the model were made in a similar way. According to methodological studies, the experimental accuracy band in deriving the Stanton number this way was from $15 \%$ to $20 \%$. The locations of the measurement points on both the upper side (the leeside) and the bottom side (the wind-side) of the model are indicated in Figure 13.

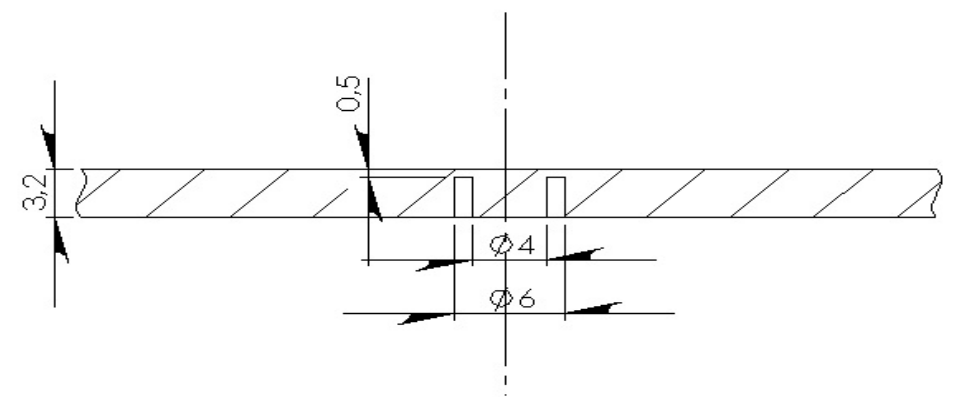

Figure 13: Installation and dimension of thermocouple installation. 


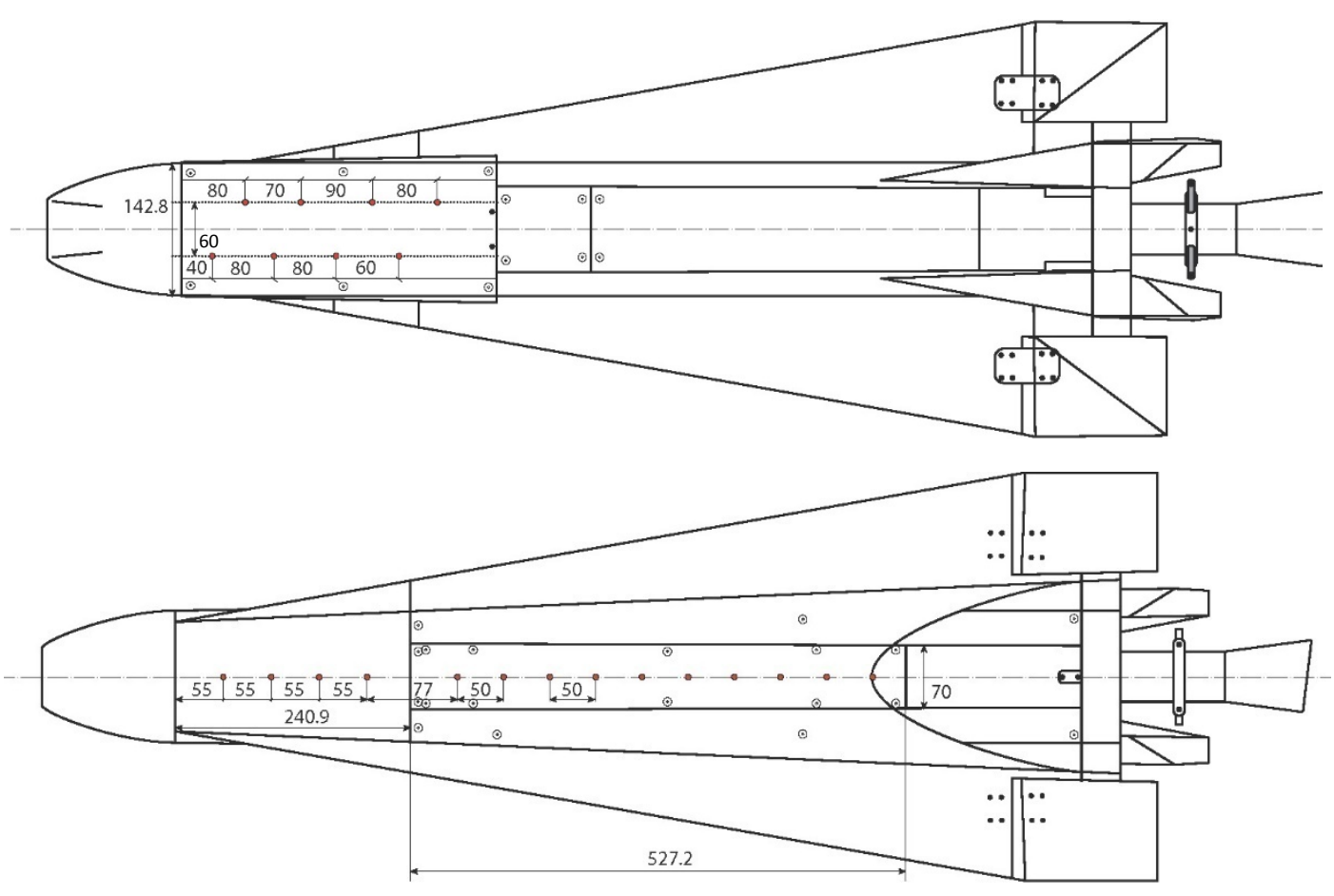

Figure 14: Location of thermocouples on leeward (top) and windward side (bottom).

The local flow parameters outside of the boundary layer on the wind- and leeside of the model used for calculations of local heat transfer coefficients, were determined approximately using relations for the oblique shock-waves and Prandtl-Meyer expansion flows, using the local angles of inclination of the model surface to the free-stream flow. The values determined in this way are given in Table 8. These parameters are used to determine local equilibrium temperatures for laminar and turbulent boundary layers, and also corresponding Stanton and Reynolds numbers:

$$
\begin{gathered}
T_{r_{\text {lam }}}=T_{\delta}\left(1+0,168 M_{\delta}^{2}\right) T_{r_{\text {.turb }}}=T_{\delta}\left(1+0,178 M_{\delta}^{2}\right), \\
S t_{\delta}=\frac{\alpha_{\delta}}{\rho_{\delta} v_{\delta} c_{\delta}}, \operatorname{Re}_{\delta}=\frac{\rho_{\delta} v_{\delta}}{\mu_{\delta}} \times \rho_{\delta} v_{\delta}=0.0697 \frac{P_{\delta} M_{\delta}}{\sqrt{T_{\delta}}},
\end{gathered}
$$

Where $P_{\delta}, M_{\delta}$ and $T_{\delta}$ are the local flow parameters outside of the boundary layer. Stanton numbers obtained from the experiment are compared with their reference values corresponding to laminar and turbulent boundary layers, i.e. for laminar boundary layer [14]:

$$
S_{\delta \text { lam }}=0,415 \operatorname{Re}_{\delta}^{-0.5}\left(1+0.168 M_{\delta}^{2}\right)^{-0.116}\left(T_{w} / T_{r}\right)^{-0.116},
$$

and for turbulent boundary layer [15]:

$$
{ }^{S t} \delta \text { turb }=0,028 \operatorname{Re}_{\delta}^{-0.18}\left(1+0.178 M_{\delta}^{2}\right)^{-0.47}\left(T_{w} / T_{r}\right)^{-0.24}
$$

The correlations used by ESA are derived from the skin friction correlations of White [35] using the Reynold's analogy. The laminar Stanton number results then into:

where $T^{*}$ is Eckert's reference temperature, defined as:

$$
S t_{e, \text { lam }}=\frac{C_{f e, l a m}}{2 \operatorname{Pr}^{2 / 3}}=\frac{1}{2 \operatorname{Pr}^{2 / 3}} \frac{0.664}{R e_{x e}^{2}} \sqrt{\frac{\mu^{*}}{\mu_{e}} \frac{T_{e}}{T^{*}}}
$$

The turbulent correlation is given by:

$$
\frac{T^{*}}{T_{e}}=0.5+0.039 M a_{e}^{2}+0.5 \frac{T_{w}}{T_{e}}
$$


where $S^{2}$ is van Driest's compressibility factor $F_{c}$.

$$
S t_{e, t u r}=\frac{C_{f e, t u r}}{2 \operatorname{Pr}^{2 / 3}}=\frac{1}{2 \operatorname{Pr}^{2 / 3}} \frac{0.455}{S^{2} \ln ^{2}\left(\frac{0.06}{S} \operatorname{Re}_{x e} \frac{\mu_{e}}{\mu_{w}} \sqrt{\frac{T_{e}}{T_{w}}}\right)}
$$

\begin{tabular}{|c|c|c|c|c|c|c|c|}
\hline AoA & Location & $\begin{array}{c}P_{\delta} \\
{\left[\mathrm{N} / \mathrm{m}^{2}\right]}\end{array}$ & $\begin{array}{c}T_{\delta} \\
{[\mathrm{K}]}\end{array}$ & $\begin{array}{l}M \delta \\
{[-]}\end{array}$ & $\begin{array}{c}\rho_{\delta} \mathrm{V}_{\delta} \\
{\left[\mathrm{kg} / \mathrm{m}^{2} / \mathrm{sec}\right]}\end{array}$ & $\begin{array}{c}T_{\text {rlam }} \\
{[\mathrm{K}]}\end{array}$ & $\begin{array}{l}\mathbf{T}_{\mathrm{r}, \mathrm{tur}} \\
{[\mathbf{K}]}\end{array}$ \\
\hline \multirow[t]{2}{*}{$\alpha=0$} & Wind-side & 1360 & 84.4 & 5.92 & 61.05 & 581.3 & 610.9 \\
\hline & Lees & 525 & 62.7 & 6.99 & 32.3 & 577.4 & 608.0 \\
\hline \multirow[t]{2}{*}{$\alpha=2^{\circ}$} & Wind-side & 1801 & 94.4 & 5.56 & 71.7 & 584.7 & 613.8 \\
\hline & Lees & 360 & 56.3 & 7.41 & 24.8 & 575.6 & 606.6 \\
\hline \multirow[t]{2}{*}{$\alpha=3.6^{\circ}$} & Wind-side & 2206 & 102.5 & 5.29 & 80.4 & 584.3 & 613.1 \\
\hline & Lees & 279 & 52.4 & 7.72 & 20.8 & 577.1 & 608.3 \\
\hline \multirow[t]{2}{*}{$\alpha=12^{\circ}$} & Wind-side & 5678 & 173.1 & 3.81 & 114.6 & 595.2 & 620.4 \\
\hline & Leeside & 46 & 31.3 & 10.22 & 5.88 & 580.9 & 613.2 \\
\hline
\end{tabular}

Table 8: Estimated edge values on the lee- and windward side of the fuselage directly after the nose

\section{Numerical Flow Simulations}

Full details of the applied CFD simulations and results can be found in [30]. Only the major elements are repeated here for clarity. ESA resolved the flow field with the TAU-code of DLR[24]. The air thermal and transport properties are computed under the assumption of chemical equilibrium with five species, namely $\mathrm{N}_{2}$, $\mathrm{O}_{2}, \mathrm{NO}, \mathrm{N}$ and $\mathrm{O}$. The originally proposed model by Spalart and Allmaras [24] provides the turbulent closure of the RANS equations. Since the laminar Pr number varies accordingly to the equilibrium model, a constant laminar to turbulent Prandtl number ratio of 0.8 is set to better approximate the turbulent part of the heat flux. The eddy to laminar viscosity ratio is set to 0.1 at the far-field and inflow boundaries. The vehicle surfaces are considered in radiative thermal equilibrium with an emissivity coefficient $(\epsilon)$ of 0.4 .

The fluxes in the Navier-Stokes equations and the eddy viscosity model are discretized accordingly to the upwind second-order AUSMDV scheme by Wada and Liou [25] with a shock fix to prevent the carbuncle phenomenon. A least-square reconstruction of the gradients [26][27] is used, which proves more accurate than the Green-Gauss approach in case of hybrid grids. Finally, the RANS equations are integrated towards the steady solution by means of a backward Euler time-relaxation scheme.

The symmetrical domain around the EFTV is discretized into a hybrid grid of around 5 million nodes (11 million elements) depending on the aileron deflection angle. A full domain, roughly twice as large, is considered for the cases of slip angle and asymmetrical flap deflection.

The surface grid is unstructured triangular but for the leading edges of nose, wings, ailerons and vertical fins. A structured-squared grid was considered for improved reconstruction of the peak heat fluxes over these surfaces. The grid refining within the boundary layer consists on a prismatic extrusion of the surface mesh up to $37 \mathrm{~mm}$ or $55 \mathrm{~mm}$ from the wall, depending on the first cell height. The height of the first cell ranges from 10 $\mu \mathrm{m}$ to $15 \mu \mathrm{m}$ (decreased further to $5 \mu \mathrm{m}$ on the leading edges). The prismatic extrusion comprises 40 cells with increasing height from the wall at a stretching ratio of 1.17 .
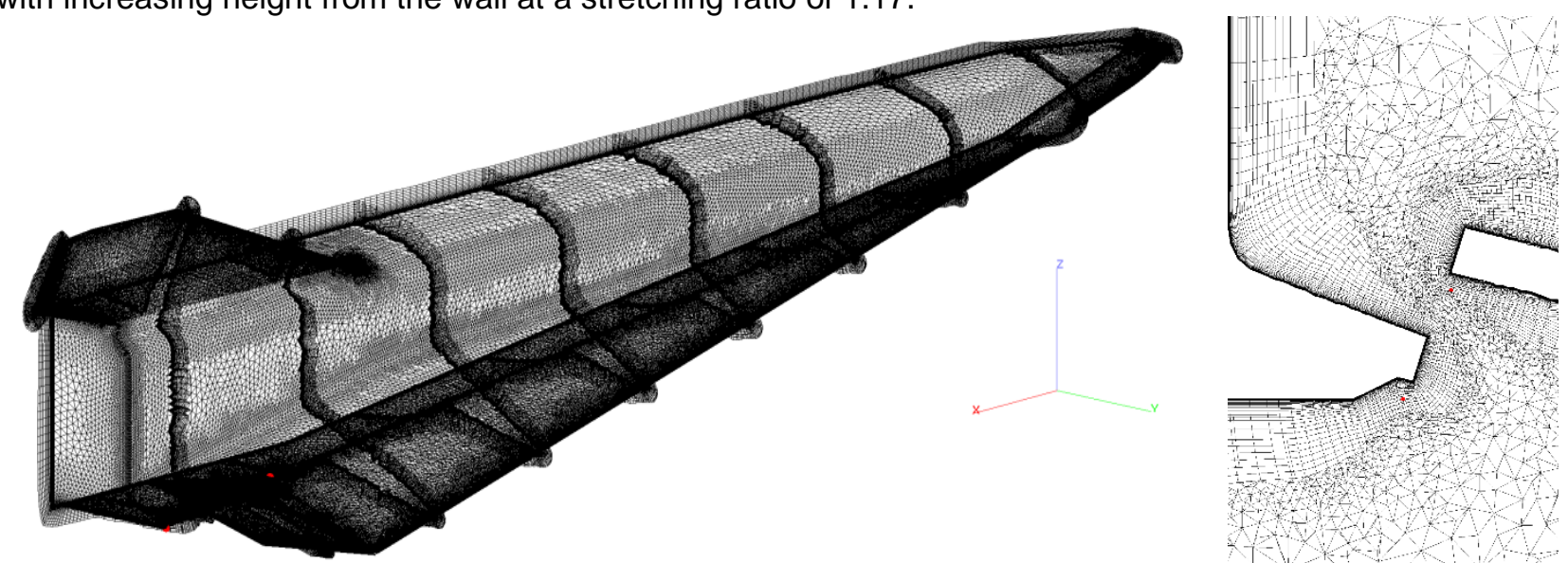

Figure 15. Overview of the surface and prismatic meshes (left) and detail at the fuselagelaileron gap (right). 
CIRA has employed the commercial code ANSYS FLUENT ${ }^{\circledR}$, which solves the Reynolds Averaged NavierStokes (RANS) equations on hybrid grids by means of the finite volume approach. FLUENT ${ }^{\circledR}$ uses a Flux Difference Splitting (FDS) second-order upwind scheme (least square cell based) for the spatial reconstruction of convective terms, while for the diffusive fluxes a cell-centred scheme is applied. An implicit scheme was considered for time integration. Regarding air physical modelling for present applications, a perfect gas model is employed (density by ideal gas law). The specific heat at constant pressure and the thermal conductivity are represented as polynomial functions of temperature (from kinetic theory of gases) and whereas the laminar viscosity follows the classical law of Sutherland. The turbulent closure is based upon the Spalart-Allmaras model. EFTV's surfaces have been assumed in radiative equilibrium, with emissivity coefficient $\varepsilon=0.4$ (asymptotic value for $\mathrm{ZrO} 2$ coating), with the exception of Mach=2 flight condition for which adiabatic wall temperature has been assumed.

The computational grids were generated with the ICEMCFD ${ }^{\circledR}$ software. The unstructured hybrid grids are composed of tetrahedrons in the outer flow and prisms inside the boundary layer. A representative surface grid is shown in Figure 15. Typically for the present flight conditions, the computational grid consists of 10 million cells in half configuration. A $\mathrm{y}^{+}$-parameter in the order of one $\mathrm{y}^{+}=\mathrm{O}(1)$ was verified by the turbulent simulations.
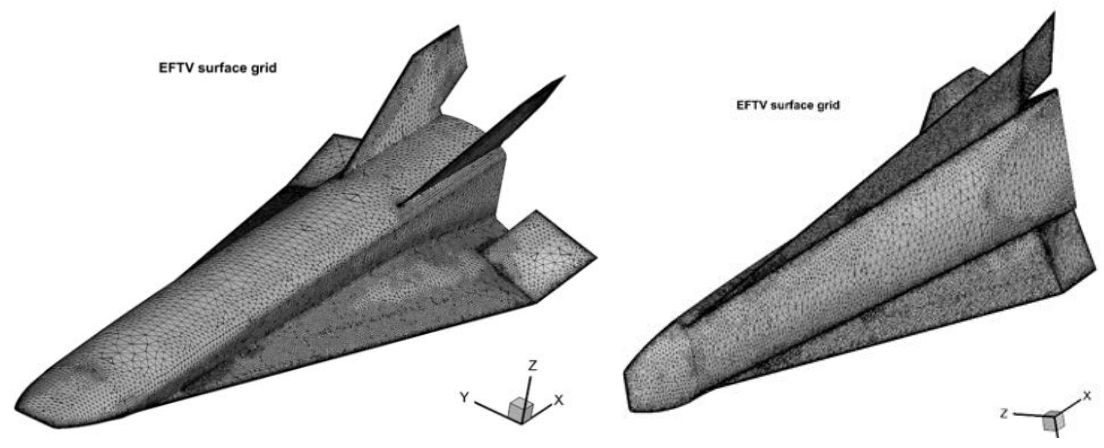

Figure 16.EFTV surface grid

TSAGI performed the CFD simulations also with the commercial code ANSYS FLUENT ${ }^{\circledR}$. Numerical studies carried out in the framework of the Reynolds averaged Navier-Stokes equations. On the wall it was established the condition of radiative equilibrium, with emissivity coefficient $\varepsilon=0.4$. The SST $k-\omega$ turbulence model supplemented by the Langtry-Menter laminar-turbulent transition model was used to take into account the transition phenomenon.

Computational unstructured grids of 20 million cells for half configuration were used for the calculations. In the boundary layer about 35 cells were located in average. Studies were carried out for the full-scale model of $L=3.29 \mathrm{~m}$ at Mach $M=7$. The Reynolds number was calculated by the model length and corresponds to the value $\operatorname{Re}_{L} \approx 12^{*} 10^{6}$.

Figure 16 and Figure 17 show the area of the laminar-to-turbulence transition for $M=7$, at zero angle of attack on the lower and upper surfaces of the EFTV model with the deflected ailerons $\left(\delta=15^{\circ}\right)$.

One way of determining the laminar-turbulent transition region is based on the value of the turbulence intensity parameter calculated by formula: $T u=\frac{\sqrt{2 / 3 k_{\delta}}}{U_{\delta}} \cdot 100 \%$, where $k_{\delta^{-}}$the kinetic energy of turbulence, $U_{\delta^{-}}$speed. It was assumed that the loss of the laminar layer stability and the beginning of the flow transition occurs at Tu> $0.5 \%$. Figure 16 shows the flow transitional areas in the internal volume of the computational domain obtained by the criterion of Tu> $0.5 \%$. All grid cells where Tu> $0.5 \%$ are painted in red. According to Figure 17, transition in the symmetry plane on the windward side occurs at a distance of about $\approx 1.3 \mathrm{~m}$ from the leading edge, and on the leeward side at $\approx 1.8 \mathrm{~m}$.

The intermittency distribution y on the wall is shown in Figure 17. As shown in Figure 17, on smooth surfaces (fuselage, wing) where the flow is relatively homogeneous, the transition takes place in a fairly narrow area, and the transition line seems quite clear. However, areas of complex eddy flows, for example, at the wingfuselage junction, the transition area is strongly blurred and covers a significant portion of the model surface. 

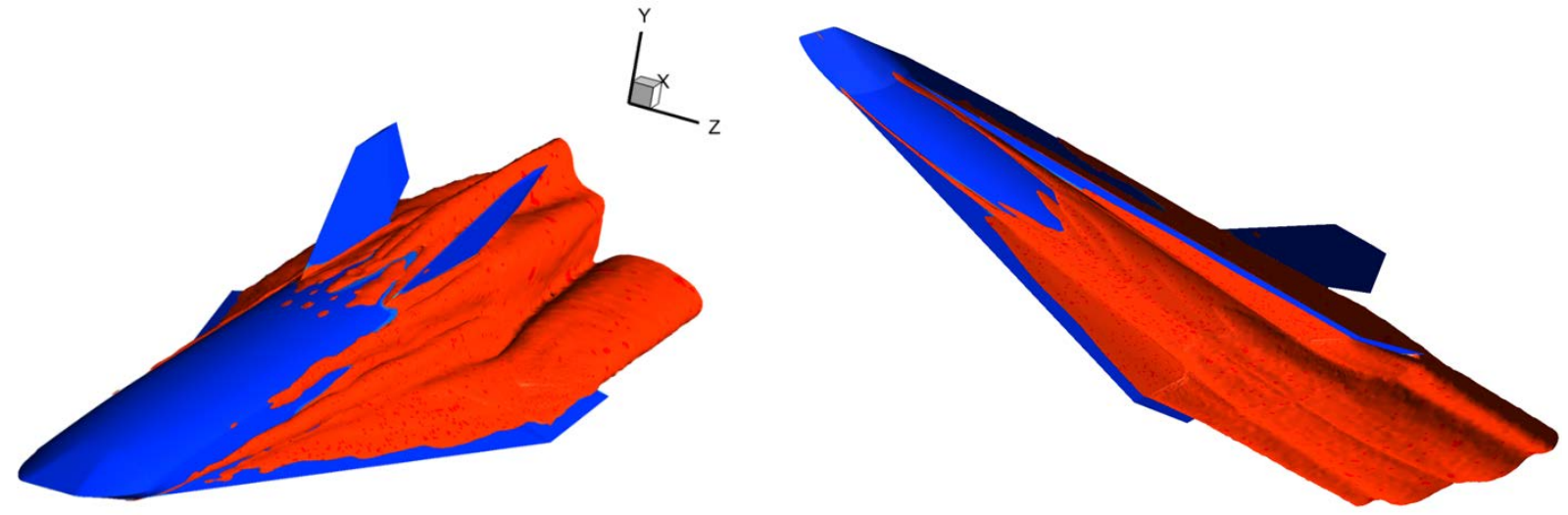

Figure 17: Transitional flow areas on leeward (left) and windward (right) sides obtained by the criterion of $\mathrm{Tu}>0.5 . \mathrm{M}=7, \mathrm{AOA}=0^{0}$.

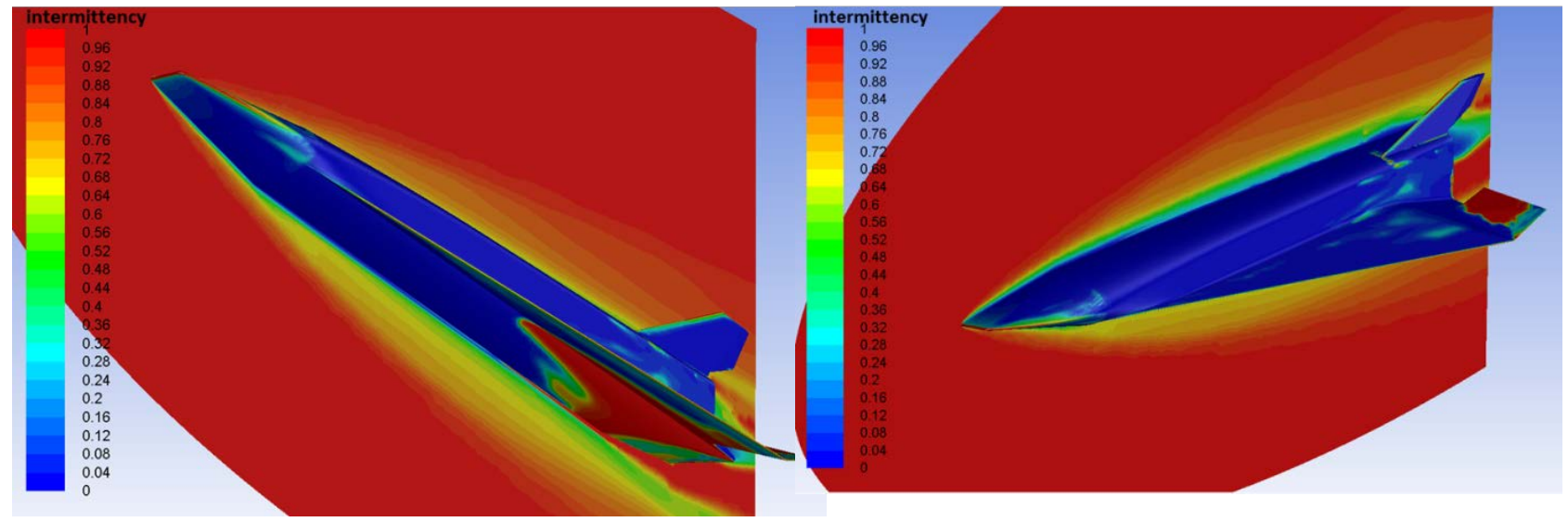

Figure 18: Intermittency distribution on windward (left) and leeward (right) sides. $M=7, A o A=0^{0}$.

\section{Experimental Results}

In Figure 19, the experimental measurements for the clean configuration, i.e. without any perturbation located on windward (bottom) or leeward side (top), are compared with correlations and CFD simulations for 3 different angles of attack, i.e. AoA $=0^{\circ}, 3.6^{\circ}$ and $12^{\circ}$. The correlations used by TsAGI and ESA are reported earlier in the article. One should take notice that the empirical correlations used are based upon flat plate and hence cannot account for any three-dimensional flow aspects.

The laminar correlations seem to correspond rather well with the CFD and experimental (pre-transitional) values on the windward side given the experimental uncertainty bands. For the leeward side the situation is similar for $A O A=0^{\circ}$ and $3.6^{\circ}$ but the difference deviates at higher angles of attack. There, the laminar CFD values do attain levels corresponding to those for the turbulent correlations. This indicates that the flat plate assumption is no longer valid as the three-dimensional features dominate the flow.

Considering the experimental values, one notices that at $A \circ A=0^{\circ}$ the flow remains laminar till at least $x=0.59 \mathrm{~m}$ on both sides of the vehicle. The flow becomes transitional on the windward side beyond $x=0.59 \mathrm{~m}$ but remains far from the fully turbulent empirical or CFD values. No assessment could be done on the leeward side further downstream due to the lack of sensors beyond $x=0.45 \mathrm{~m}$. At $A \circ A=12^{\circ}$, the transition point on the windward lies somewhere between $0.44 \mathrm{~m}<x<0.59 \mathrm{~m}$. Still, the transition seems not to be completed and the heat flux remains somewhat between the laminar and turbulent values. This is in line with the earlier transition criteria where transition onset is predicted at $x_{t r} / L<0.5$ (Table 3 ). For the same $A o A=12^{\circ}$ on the leeward side, one notices that the experimental values coincide with the laminar CFD evolution but for some points above the turbulent correlations. Though the raising Stanton evolution as from midway the fuselage would insinuate a transitional phenomenon, it is actually a vortical structure on the leeward side which causes the raise up to 
a maximum (see Figure 20). The absence of any transition on the leeside as listed in Table 3 seems to confirm this tendency. For the AoA $=3.6^{\circ}$, windward transition seems to occur around $x=0.59 \mathrm{~m}$ and reaches nearly the turbulent value at $x=0.79 m$ after which it starts to decline again. The corresponding leeward side shows more or less the same evolution as for $A o A=12^{\circ}$, i.e. affected by a secondary flows, but the CFD simulation was not able to reproduce this behaviour and this remains an open question.

Figure 21 provides an evolution of the heat transfer in function of the angle of attack. It is clear that the flow becomes transitional beyond $x=0.45 \mathrm{~m}$ on the windward side. On the leeward side the experiments for AoA $=$ $0^{\circ}$ and $2^{\circ}$ are aligned with the laminar correlations whereas those for $A \circ A=12^{\circ}$ are aligned with the laminar CFD. It is believed that for AoA $=3.6^{\circ}$ the computed St number is very sensitive to the pattern and strength of the secondary flows.

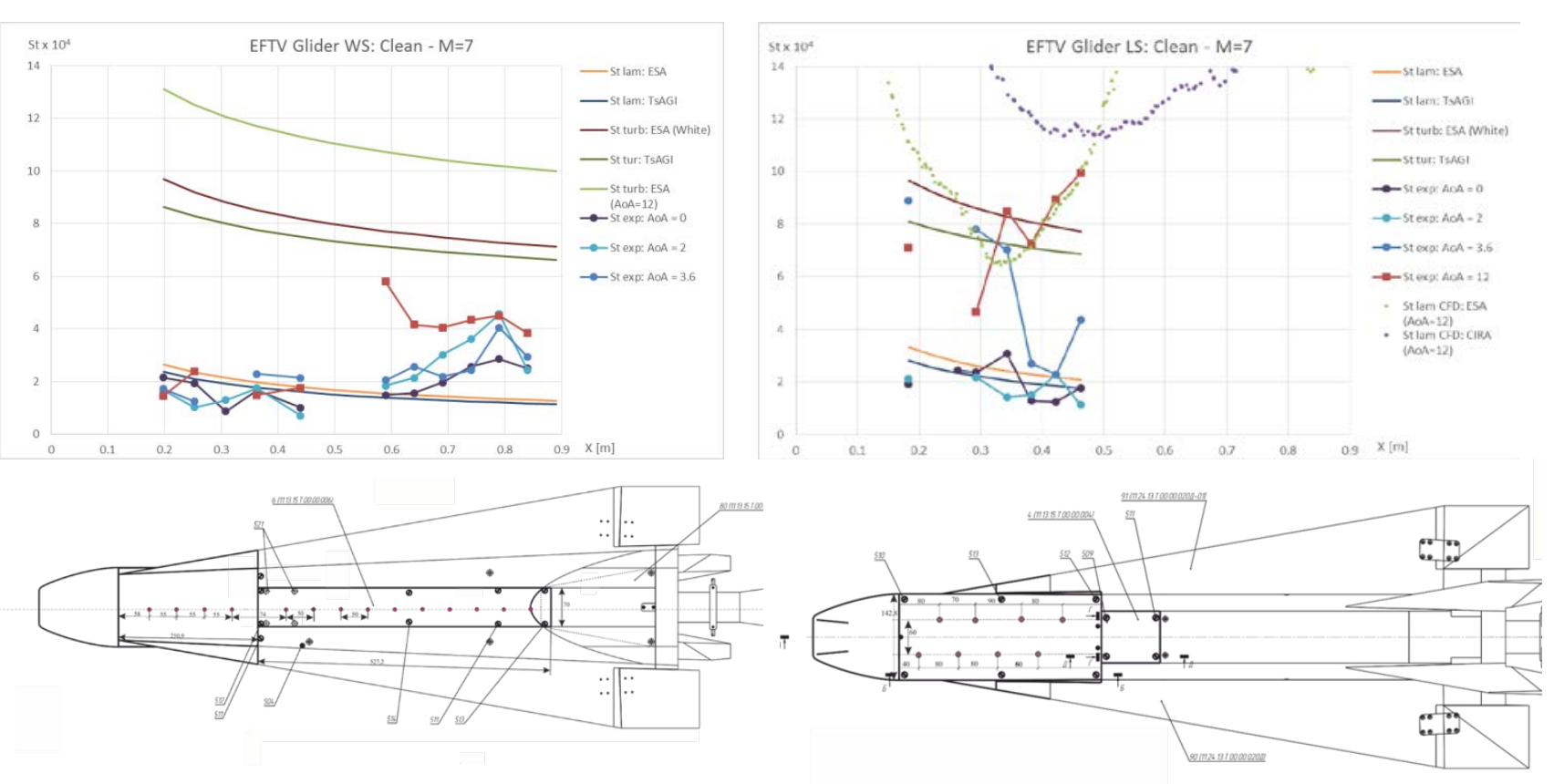

Figure 19: Experimental Stanton numbers on clean configuration on windward side (left) and leeward side (right) at different angles of attack: $A O A=0^{\circ}, 2^{\circ}, 3.6^{\circ}$ and $12^{\circ}$

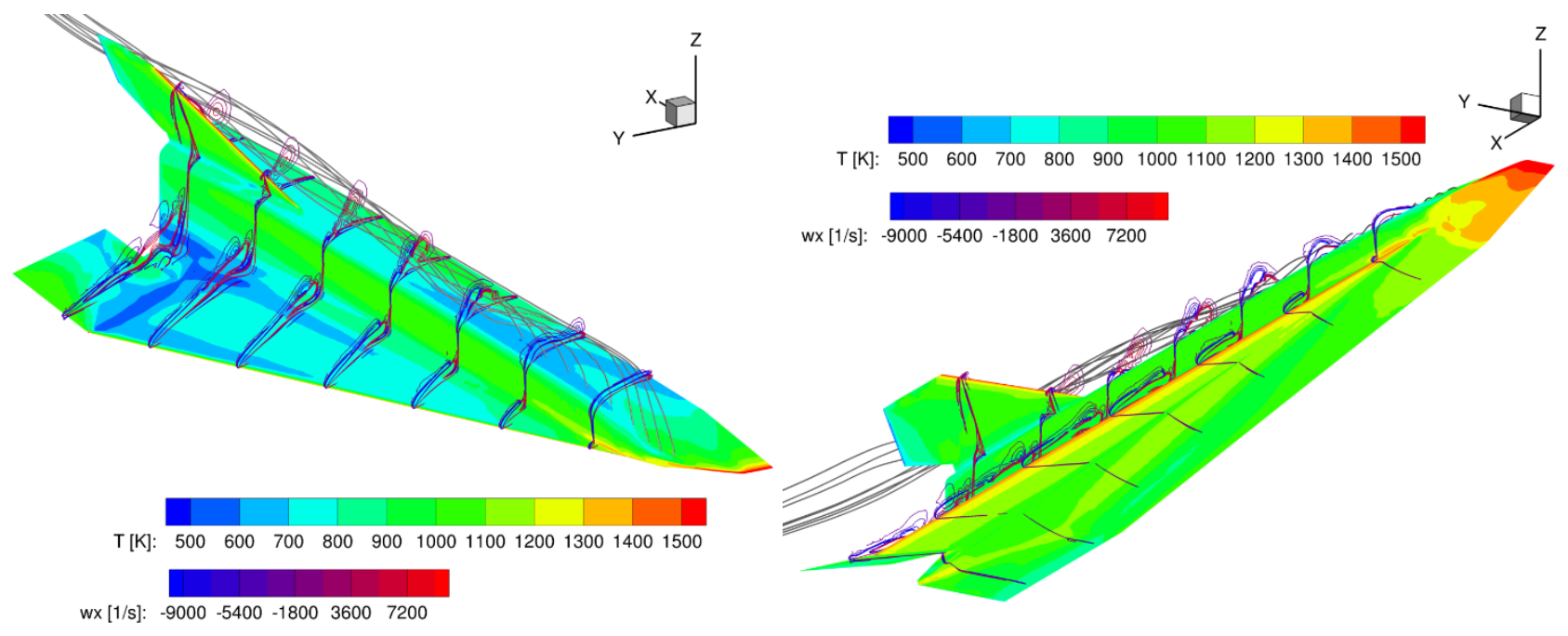

Figure 20: Radiative equilibrium wall temperatures $(\varepsilon=0.4)$ and vortical structures $\Omega_{\mathrm{x}}$ at Mach 7 on leeward (left) and windward side (right) for $A \circ A=12^{\circ}$ 


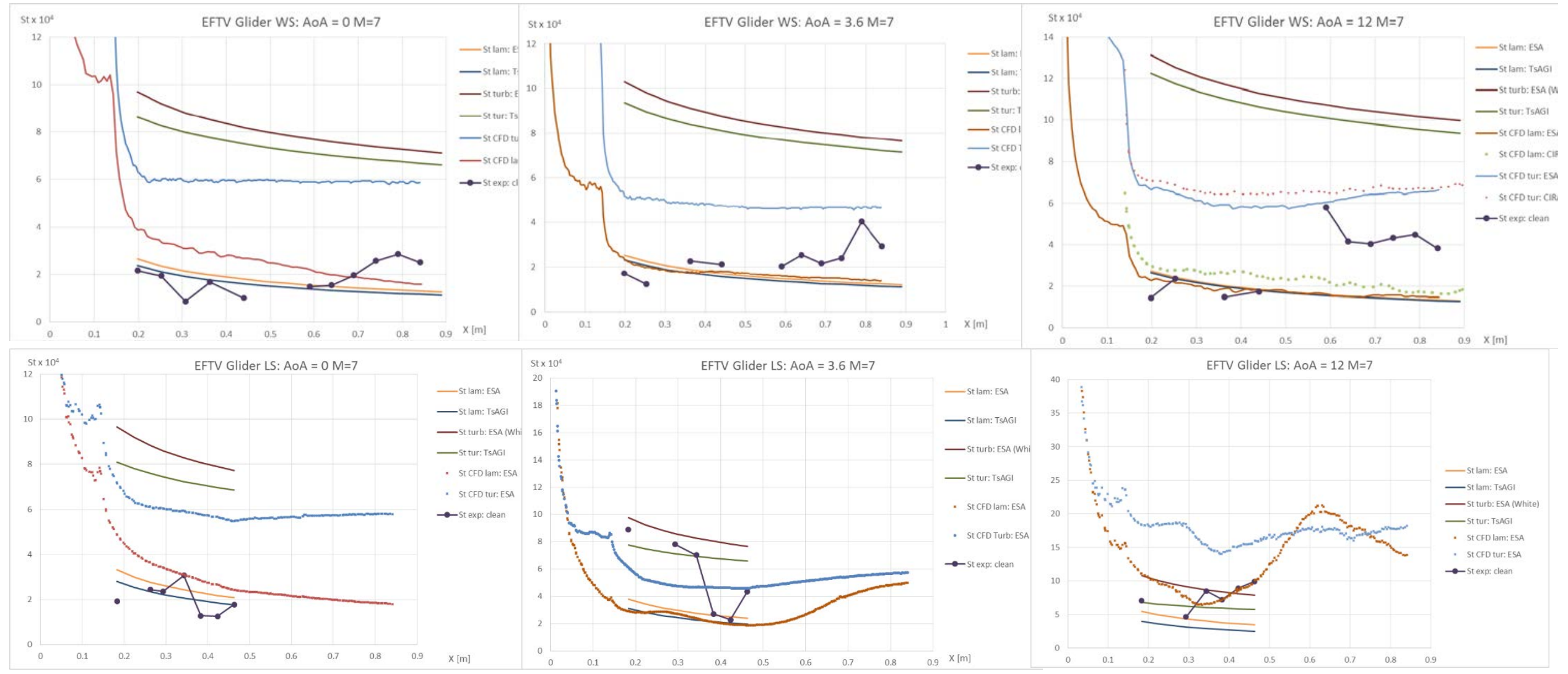

Figure 21: Experimental Stanton numbers on clean configuration on windward side (top) and leeward side (bottom) at different angles of attack: AoA $=0^{\circ}$ (left), $3.6^{\circ}$ (middle) and $12^{\circ}$ (right) 
In Figure 22, the experimental measurements for the configuration with various perturbations present on windward (top) and leeward side (bottom) are compared with correlations and CFD simulations for 3 different angles of attack, i.e. AoA $=0^{\circ}, 3.6^{\circ}$ and $12^{\circ}$. The used correlations by TSAGI and ESA are described above in the article. Whereas Figure 21 shows the experimental results obtained with clean configuration of the model, Figure 22 includes only those perturbation elements which are estimated not to trigger transition earlier for the flight configuration with respect to a smooth surface, i.e. a maximum estimated at $h<3.7 \mathrm{~mm}$ (Table 5). The tripping devices concerned are the distributed cylindrical perturbations with a height of $\mathrm{k}_{\mathrm{s}}=0.35 \mathrm{~mm}(1 \mathrm{~mm}$ on flight-scale) and a wire with a diameter of $\mathrm{k}_{\mathrm{w}}=0.5 \mathrm{~mm}$ or $\mathrm{k}_{\mathrm{w}}=1 \mathrm{~mm}$ (respectively $-1.43 \mathrm{~mm}$ or $-2.86 \mathrm{~mm}$ on flight-scale). The complete set of the results obtained in the wind tunnel T-116 are presented on Figure 23.

On the windward side, the transition onset and extent do not seem to be really impacted by the triggering devices though there is likely an upstream shift at $A 0 A=12^{\circ}$. However, some local effects are apparent prior to the transition point. At $A o A=3.6^{\circ}$, the data corresponding to $\mathrm{k}_{\mathrm{w}}=1 \mathrm{~mm}$ is still laminar for $\mathrm{x} / \mathrm{L}<50 \%$ and less irregular than for the case with $\mathrm{k}_{\mathrm{w}}=0.5 \mathrm{~mm}$. This could be due to a lower deflection for the 16 times stiffer wire when $\mathrm{k}_{\mathrm{w}}=1 \mathrm{~mm}$. For $\mathrm{k}_{\mathrm{w}}=0.5 \mathrm{~mm}$, the results become more credible for $\mathrm{AoA}=12^{\circ}$.

On the leeward side, the same tripping devices are placed as on the windward side. For $A 0 A=0^{\circ}$, the transition onset around $x / L=40 \%$ is not really impacted by the listed tripping devices. The variations noticed prior to transition are within the $20 \%$ accuracy of the experimental sensors. For AoA $>3.6^{\circ}, 3 \mathrm{D}$ effects start to step in again as was the case for the clean configuration. The cases for $k_{s}=0.35$ and $k_{s}=0.7$ follow the laminar trend. The case for $k_{w}=0.5$ seems to trigger local turbulent strips but dies out to laminar values to pick up the three-dimensional effect.

\section{Concluding Remarks}

The present paper has dealt with the transitional aspects for the EFTV glider at various points along the trajectory. To estimate the onset and extent of transition, various methods were deployed. Empirical correlations were not only used to predict the transitional parameters, but helped in defining the optimal leading edge radii. CFD simulations supported the transitional criteria by characterizing the boundary layer at critical points along the vehicle. Similar approaches were used to estimate critical heights of perturbations. All of this was finally verified experimentally in a wind tunnel at representative flight conditions. It helped understanding as well what type of imperfections could be accepted for the final integration and assembly of the flight vehicle.

Generally, the correlations for a clean configuration without any perturbation seem to agree with what is observed experimentally in the wind tunnel T-116 at TsAGI. On the windward side the transition onset starts for the various attitudes around midway whereas no clear transition is detected on the leeward side. The flow pattern on this upper side is quite affected by three-dimensional vortical structures which render the heat loads higher than one would expect from turbulent correlations on a flat plate. The various heights and sizes of perturbations enabled the critical dimension to trigger transition. The subcritical heights for which transition onset was not or hardly changed are in line with the correlations. Dedicated analyses on how steps and gaps would form during thermal expansion throughout the trajectory should indicate whether one would face the occurrence of protuberance going beyond the critical height throughout the mission.

\section{Acknowledgments}

This work was performed within the 'High-Speed Experimental Fly Vehicles-International' project fostering International Cooperation on Civil High-Speed Air Transport Research. HEXAFLY-INT, coordinated by ESAESTEC, is supported by the EU within the 7th Framework Programme Theme 7 Transport, Contract no.: ACPOGA-2014-620327 and by the Ministry of Industry and Trade, Russian Federation. Further info on HEXAFLYINT can be found on http://www.esa.int/hexafly-int. 


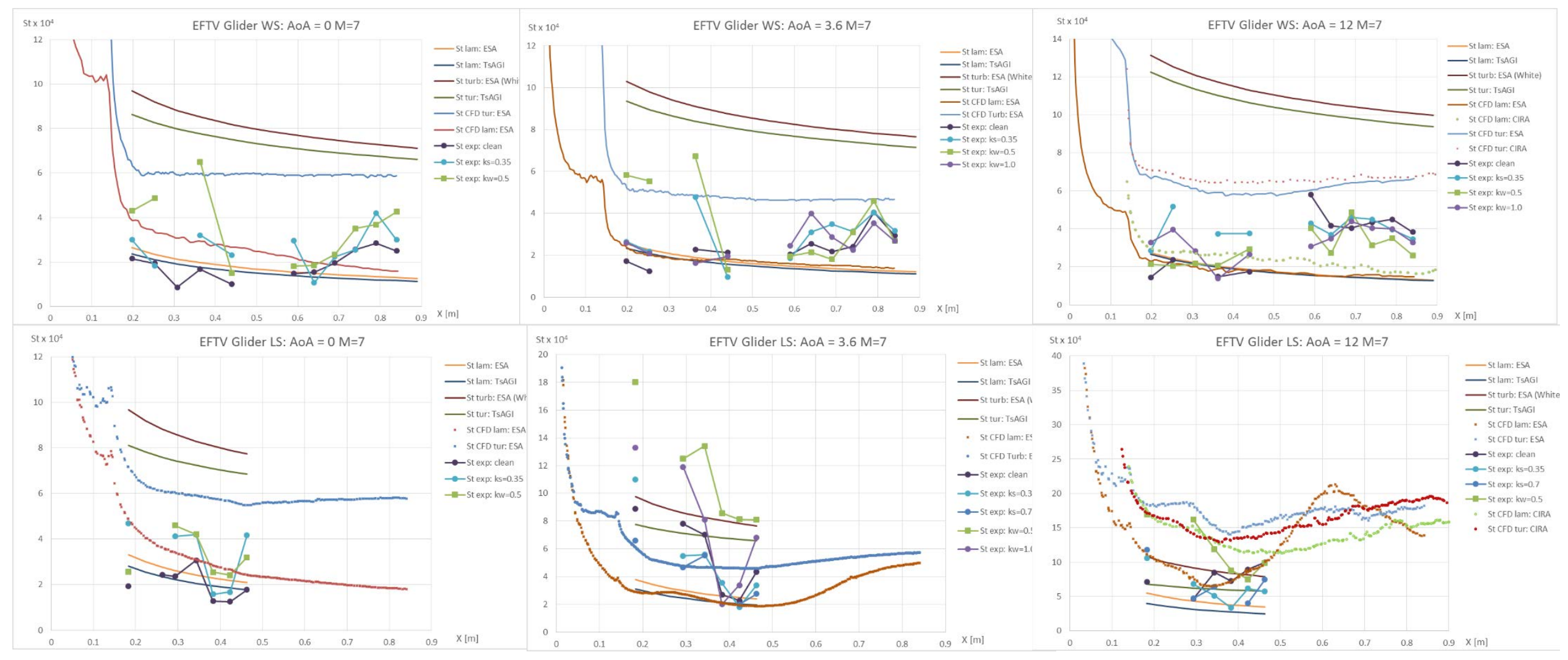

Figure 22: Experimental Stanton numbers on configuration with tripping devices (distributed and a continuous wire) on windward side (top) and leeward side (bottom) at different angles of attack: $A O A=0^{\circ}$ (left), $3.6^{\circ}$ (middle) and $12^{\circ}$ (right) 


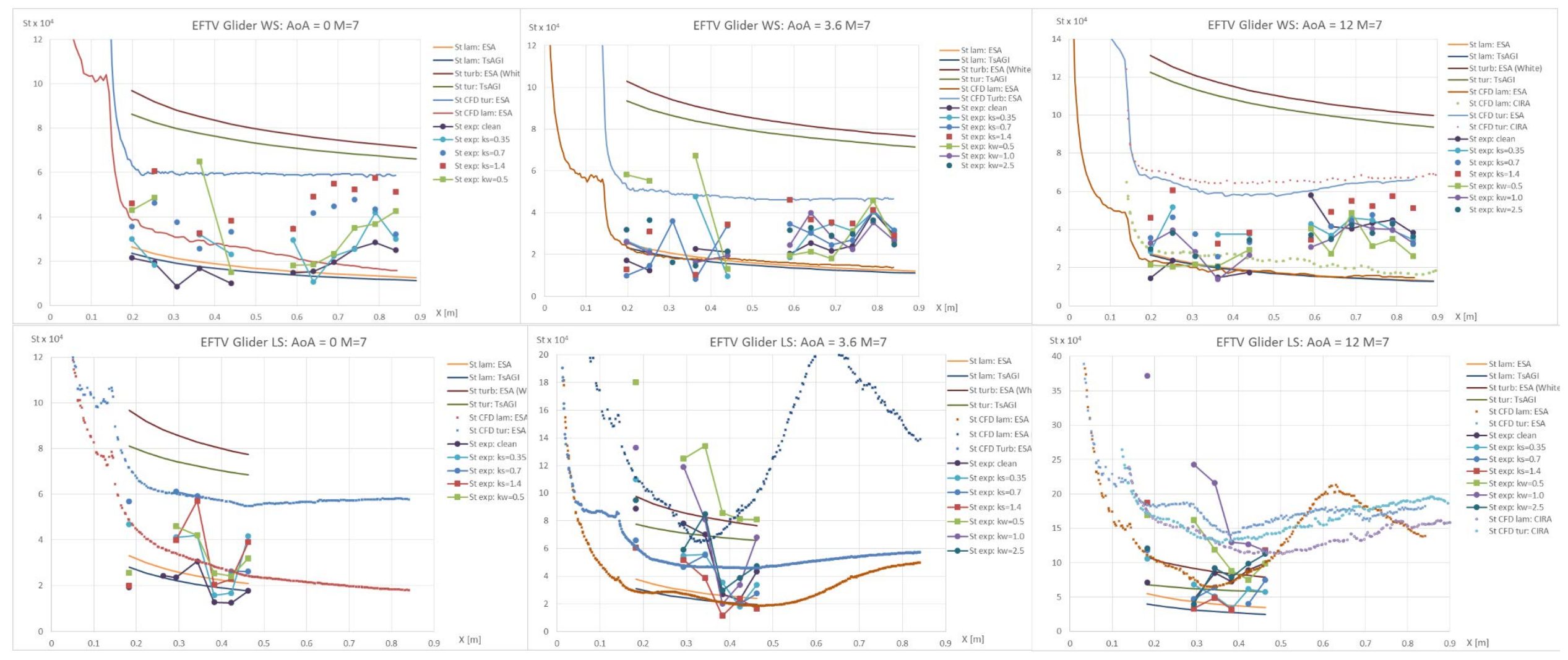

Figure 23: Experimental Stanton numbers on configuration with all tripping devices included (distributed and a continuous wire) on windward side (top) and leeward side (bottom) at different angles of attack: $A O A=0^{\circ}$ (left), $3.6^{\circ}$ (middle) and $12^{\circ}$ (right) 


\section{References}

[1] Steelant J., 'Achievements Obtained for Sustained Hypersonic Flight within the LAPCAT Project', 15th AIAA International Space Planes and Hypersonic Systems and Technologies Conference, 28/04- 01/05-2008, Dayton, Ohio, USA, AIAA-2008-2578.

[2] Steelant, J., Varvill R., Defoort S., Hannemann K. and Marini M., 'Achievements Obtained for Sustained Hypersonic Flight within the LAPCAT-II Projet', 20 ${ }^{\text {th }}$ AIAA International Space Planes and Hypersonic Systems and Technologies Conference, AIAA-2015-3677, 5-8 July, Glasgow, Scotland. 2015.

[3] Steelant J., 'ATLLAS: Aero-Thermal Loaded Material Investigations for High-Speed Vehicles', 15 ${ }^{\text {th }}$ AIAA International Space Planes and Hypersonic Systems and Technologies Conference, 28/04-01/05-2008, Dayton, Ohio, USA, AIAA2008-2582.

[4] Steelant J., Dalenbring M. ., Kuhn M., Bouchez M. and von Wolfersdorf J., 'Achievements obtained within the ATLLAS-II Project on Aero-Thermal Loaded Material Investigations for High-Speed Vehicles', 21st Int. Space Planes and Hypersonic Systems and Technology Conference, AIAA-2017-xxxx, 6-9 March 2017, Xiamen, China, submitted.

[5] Steelant J., 'Evolutionary Technology Developments for High-Speed Transportation', Aerodays 2015, 20-23/10/2015, London, UK.

[6] Steelant J., Langener T., Hannemann K., Riehmer J., Kuhn M., Dittert C., Jung W., Marini M., Pezzella G., Cicala M. and Serre L., 'Conceptual Design of the High-Speed Propelled Experimental Flight Test Vehicle HEXAFLY', $20^{\text {th }}$ AIAA International Space Planes and Hypersonic Systems and Technologies Conference, AIAA-2015-3539, 5-8 July, Glasgow, Scotland. 2015.

[7] Favaloro N., Pezzella G., Carandente V., Scigliano R., Cicala M., Morani G. and Steelant J., 'Design Analysis of the High-Speed Experimental Flight Test Vehicle HEXAFLY-International', 20th Int. Space Planes and Hypersonic Systems and Technology Conference, AIAA-2015-3607, 5-8 July 2015, Glasgow, UK.

[8] Steelant J., Marini M., Pezzella G., Reimann B., Chernyshev S.L., Gubanov A.A., Talyzin V.A., Voevodenko N.V., Kukshinov N.V., Prokhorov A.N., Neely A.J, Kennel C., Verstraete D., Buttswort D., 'Numerical and Experimental Research on Aerodynamics of High-Speed Passenger Vehicle within the HEXAFLY-INT Project', 30th Congress of the International Council of Aeronautical Sciences (ICAS), 25-30/09/2016, Daejeon, Korea.

[9] Simeonides G. A., 'Laminar-Turbulent Transition Correlations in Supersonic/Hypersonic Flat Plate Flow', 24 ${ }^{\text {th }}$ International Congress of the Aeronautical Sciences, 29 August - 3 September 2004, Yokohama, Japan.

[10] Simeonides G. A. and Kosmatopoulos E., 'Laminar-Turbulent Transition Correlations in Supersonic/Hypersonic Flat Plate Flow', 25 ${ }^{\text {th }}$ International Congress of the Aeronautical Sciences, 3 - 8 September 2006, Hamburg, Germany.

[11] Simeonides G. A., 'Laminar-Turbulent Transition Correlations in Supersonic/Hypersonic Flat Plate Flow - Attached versus Separated Flow', 26 ${ }^{\text {th }}$ International Congress of the Aeronautical Sciences, 14 - 19 September 2008, Anchorage, Alaska, USA.

[12] Simeonides G. A., ' Correlation of Laminar-Turbulent Transition Data over Flat Plates in Supersonic/Hypersonic Flow including Leading Edge Bluntness Effects', Shock Waves (2003) 12: 497-508.

[13] Mayle R. E., 'The Role of Laminar-Turbulent Transition in Gas Turbine Engines', Journal of Turbomachinery, Vol. 113, 1991, pp. 509-536.

[14] Steelant J. and Dick E., 'Modelling of Laminar-Turbulent Transition for High Freestream Turbulence', ASME JFE, Vol. 124, No. 1, p 22-30, 2001.

[15] Di Cristina V., 'Three-Dimensional Laminar Boundary-Layer Transition on a Sharp 8-deg Cone at Mach 10', AIAA Journal, Vol. 8, No. 5, May 1970, p. 855.

[16] Berry S. et al., 'Boundary Layer Transition on X-43A', 38th AIAA Fluid Dynamics Conference, Seattle WA, USA, 2326 June 2008: AIAA-2008-3736.

[17] Berry S., Di Fulvio M. and Kowalkowski K., 'Forced Boundary Layer Transition on X-43 (Hyper-X) in NASA LaRC 20Inch Mach 6 Air Tunnel', NASA/TM-2000-210316.

[18] Schrijer F. F. J., Scarano F., van Oudheusden B. W. and Bannink W. J., 'Experiments on Hypersonic Roughness Induced Transition by Means of Infrared Thermography', Proceedings of the Fifth European Symposium on Aerothermodynamics for Space Vehicles (ESA SP-563). 8-11 November 2004, Cologne, Germany. Editor: D. Danesy, p.255.

[19] Masutti D., Chazot O., Osma C.A. and Spinosa E., 'Evaluation of 2D Roughness Induced Transition for EXPERT Vehicle Design', 16th AIAA/DLR/DGLR International Space Planes and Hypersonic Systems and Technologies Conference, October 19-22, 2009, Bremen, Germany, AIAA-2009-7399., AIAA-2009-7212.

[20] Ginoux J. J., 'Laminar Separation in Supersonic Flow', Final Report Contract AF EARO 63-45, von Karman Institute, 1963.

[21] Ginoux J. J., 'On Some Properties of Reattaching Laminar and Transitional High Speed Flows', Technical Note 53, von Karman Institute, Sept. 1969.

[22] Massutti D., 'Ground Testing Investigation of Hypersonic Transition Phenomena for a Re-Entry Vehicle', Ph.D.Thesis, Padua, June 2013.

[23] Passaro A. and Cifali G., 'Experimental Characterization of Roughness-Induced Transition on a Flat Plate at Mach 6 in the European ATLLAS-2 Programme', 8 ${ }^{\text {th }}$ Aerothermodynamics Symposium, 2 - 6 March 2015, Lisbon, Portugal.

[24] Passaro A. and Cifali G., 'Transition Experiment Test Report', ATLLAS-II Deliverable D5.3.3, 31/01/2015. 
[25] Institute of Aerodynamics and Flow Technology, German Aerospace Center (DLR), The DLR TAU Code, 2012. url: http://tau.dlr.de/.

[26] Spalart P.R. and Allmaras S.R., 'A One-Equation Turbulence Model for Aerodynamic Flows, AIAA-92-0439, 1992.

[27] Wada Y. and Liou M.S.', 'A flux splitting scheme with high-resolution and robustness for discontinuities', AIAA Paper 94-0083, 1994.

[28] Anderson W. Kyle and Bonhaus Daryl L., 'An Implicit Upwind Algorithm for Computing Turbulent Flows on Unstructured Grids', Computers Fluids Vol. 23, No. 1, pp 1-21, 1994.

[29] Haselbacher A. and Blazek J., 'On the Accurate and Efficient Discretisation of the Navier-Stokes Equations on Mixed Grids,' AIAA J. 99-33552, 1998.

[30] Pezzella G., Marini M., Reimann B. and Steelant J., 'Aerodynamic Design Analysis of the HEXAFLY-INT Hypersonic Glider', 20 ${ }^{\text {th }}$ AIAA International Space Planes and Hypersonic Systems and Technologies Conference, AIAA-20153644, 5-8 July Glasgow, Scotland. 2015.

[31] Marini M., Pezzella, Schettino A., Di Benedetto S., Fernandez-Villace V., Steelant J., Gubanov A.A., Voevodenko N.V., Reimann B. and Walton C., 'Numerical and Experimental Characterization of the HEXAFLY-INT Hypersonic Glider', 21st Int. Space Planes and Hypersonic Systems and Technology Conference, AIAA-2017-xxxX, 6-9 March 2017, Xiamen, China.

[32] Pezzella G., Carandente V., Scigliano R., Marini M. and Steelant J., 'Aerothermal Environment Methodology of the Hexafly-Int Experimental Flight Test Vehicle (EFTV)', ${ }^{\text {th }}$ European Symposium on Aerothermodynamics for Space Vehicles, 2-6 March 2015, Lisbon, Portugal.

[33] Carandente V., Scigliano R., Pezzella G., Marini M. and Steelant J., 'Finite Element thermal design of the HexaflyINT Experimental Flight Test Vehicle', $6^{\text {th }}$ European Conference for Aeronautics and Space Sciences (EUCASS), 29 June - 03 July 2015, Krakow, Poland.

[34] Kondratiev G.M. 'Regular heating regime'. Technical theoretical literature edition, 1954.

[35] Shvalev Yu. G. 'Experimental investigation of the local heat transfer in laminar boundary layer at supersonic velocities'. TsAGI scientific notes, Vol. IX, № 5, 1978.

[36] Ragulin N.F. and Shvalev Yu. G. 'Experimental investigation of the local heat transfer in turbulent boundary layer at supersonic velocities'. Journal of Engineering and Physics, Vol. XLV, №4, 1983.

[37] White F. M., 'Viscous Fluid Flow', 2 ${ }^{\text {nd }}$ edition, ISBN 0-07-069712-4, McGraw-Hill. 